\title{
Die pliozänen und quartären Pluvialzeiten der Sahara
}

\author{
Von Julrus Büdel, Würzburg \\ Mit 1 Abbildung im Text
}

\begin{abstract}
Zusammenfassung: In der betrachteten Zeitspanne (Beginn Pliozän bis Gegenwart) treten in der Sahara $\mathrm{z}$ w e $\mathrm{i}$ Typen von Pluvialen auf.

Im N-Teil der Sahara ist das Pliozän trocken, ebenso das Holozän. Im Pleistozän treten sechs Pluviale auf, die zeitlich und kausal mit den ektropischen Kaltzeiten übereinstimmen („polare Pluviale"). In der S-Hälf t e der Sahara ist das Pliozän feucht, ebenso das Holozän vom Neolithikum ab. Dazwischen ist das Pleistozän zumeist trocken, erst spät (etwa Ende Riß bis Mitte Würm) tritt ein Pluvial auf. Die S-Saum-Pluviale zeigen daher keine oder nur indirekte Beziehungen zu den ektropischen Kaltzeiten („äquatoriale Pluviale“).

Je weiter wir in die Vergangenheit zurückgehen, desto klarer zeigen die fossilen Zeugnisse eine andere Art und Verteilung der Klimagürtel an. Ihre rein rückschauende Ableitung aus dem Gegenwartsklima („klimatischer Aktualismus“) erwies sich als irreal. Daher wird versucht, von einem relativ gut rekonstruierbaren Klimazustand der Vergangenheit aus auf das Gegenwartskima als exakt bekannten Endpunkt vorzuschreiten. Als solcher Ausgangspunkt empfahl sich das Klima vom Eozän bis zur Mio-Pliozän-Wende. Hierfür wird der Begriff „Alte Tropenerde“ vorgeschlagen. Die Erde war damals durch gleichmäßig warmes Klima, das Vorherrschen von Ostwinden, einer R.otlehm-Kaolin-Verwitterung und vorherrschende Flächenbildung bis in hohe Breiten ausgezeichnet. Vereiste Polarklimate fehlten. Die zonale Klimagliederung war schwach, insbesondere traten durchlaufende Passatwüsten zurück.
\end{abstract}

Die gegen Ende der "Alten Tropenerde“ spürbare langsame Abkühlung verstärkte sich im Pliozän. Die Vergrößerung der (noch mäßig) kalten Polarhauben förderte das Druckgefälle Pol/ Äquator. Die Folge ist eine stärkere z on a l e Gliederung der Klimagürtel. Auch das Subtropenhoch tritt deutlicher hervor. Die Austrocknung der heutigen Sahara beginnt im N und setzt sich im Laufe des Pliozän bis zum S fort.

Die pleistozänen Kaltzeiten fördern dagegen die Meridional-Zirkulation. Ihre Spuren treten am N-Saum von der ersten Kaltzeit an als „Pluviale“ auf; am S-Saum erscheint ein solches erst im Jungpleistozän. Erst in der Würmzeit wird daher die Sahara von beiden Steiten her durch Feuchtgürtel eingeengt, wie es dem Idealbild A. PENCK's entsprach. Es müssen also bestimmte Züge des "Eiszeitenklimas" sich erst im Laufe des Pleistozän entwickelt und schließlich in der Würmzeit kumuliert haben.

Vier solche Entwicklungen wirkten dabei zusammen. Die beiden ersten: fortschreitende Gebirgshebungen und die allmähliche Vereisung der Nordpolargebiete fördern die Meridional-Zirkulation auf der N-Halbkugel. Die dritte: die fortdauernde Absenkung der interglazial-eustatischen Ozeanhochstände (Sizil - Milazz - Tyrrhen I - Monastir) förderte durch die Vergrößerung der Kontinentfiächen gleichfalls die Meridional-Zirkulation. Viertens wird auf Grund dieser sinkenden Ozeanstände ein verzögerter Aufbau des antarktischen Inlandeises abgeleitet. Im Ältestpleistozän noch fehlend, wurde es im Alt- und Mittelpleistozän zunächst in den Kaltzeiten, von einem bestimmten Umfang an (im Jungpleistozän) aber nur noch in den Warmzeiten weiter aufgebaut. Am größten war es wahrscheinlich zu Beginn des Würm (300-800 m mächtiger als heute). Daher wurde im Würm die S-Halbkugel besonders stark abgekühlt, rückte der thermische Äquator und der äquatoriale Regengürtel besonders weit nordwärts, so daß er auf den S-Saum der Sahara mit einem Pluvial übergreifen konnte.

$\mathrm{Sum}$ m a $\mathrm{y}$ : During the period under consideration (from the beginning of the Pliocene to present) $t w o$ types of pluvials occur in the Sahara desert.

In the northern part of the Sahara the Pliocene as well as the Holocene were dry. During the Pleistocene we find six pluvials, which coincide in time and in cause with the non-tropical cold periods ("polar pluvials"). In the southern part of the Sahara the Pliocene is humid, and so is the Holocene beginning with the neolithic Age; the Pleistocene however, mostly dry and only late (about the end of "Riß" till the middle of "Würm") we find a pluvial. The southern p'uvials do not show any or only indirect relations to the non-tropical periods ("equatorial pluvials").

The more we go back into the past, the more distinctly the fossil remains prove a type and arrangement of climatic zones different from today. To derive them from the present climate by lokking backwards ("climatic actualism") proved to be wrong. So it was tried to proced from a climate of the past, which can rather easily be reconstructed, to the well-known final point: the 
present climate. As such a climate of the past, the climate from the Eocene to the beginning of the Pliocene offered itself. For this climate we suggest the term "Old Tropical Earth". The earth at this time was characterized by a uniformly warm climate, prevailing east winds, a red clay or kaoline weathering, and a predominant formation of plaines up to high latitudes. Icy polar climates were not existing. The structure of climatic zones was vague, continuous subtropical and tropical deserts in particular were seldom.

The slow cooling setting in at the end of the "Old Tropical Earth" grew a little during the Pliocene. The enlargement of the (still moderately) cold polar caps increased the pressure drop Pole/Equator. As its consequence the zoned structure of the climatic belts became more pronounced and the subtropical high pressure zones more distinct. The drying process in the present Sahara began in the North and continued to the South during the Pliocene.

The cold periods of the Pleistocene, however, furthered the meridional circulation. They can be traced by the pluvials which occured on the north edge beginning with the first cold period, while on the south edge the first pluvial occured only during the late Pleistocene. So it was not before the period of the Würm that the Sahara was narrowed in from both sides by humid belts, which corresponds to the ideal conception of A. PENCK. Accordingly it was not before the Würm period that certain features of the cold type of the "ice age climate" must have developed and must have reached a climax.

Four such developments worked together. The first two: the progressive uplifting of mountains and the gradual icebuildging of the northern polar region stimulated the meridional circulation on the northern hemisphere. The third: the continuous sinking of the interglaciale eustatic high standing of ocean waters (Sicil - Milazz - Tyrrhen I - Monastir) furthered likewise the meridional circulation by its simultaneus enlargement of continental areas. Fourth: on account of the sinking of ocean waters a retarding increase of the antarctic inland ice is inserred. Still missing in the earlist Pleistocene, it gradually increased in the old and middle Pleistocene and here only during the cold periods; later, however, (late Pleistocene) and from a certain extent onwards only during the warm periods. Its greatest extent was probably reached at the beginning of the "Würm" (300-800 $\mathrm{m}$ thicker than today). Hence the enormous drop of temperature in the southern hemisphere during the Würm, which caused the thermic equator and the equatorial rain belt to move so far up north that pluvials could reach the southern edge of the Sahara.

\section{In halt}

I) Entwicklung des Problems

II) Wege der Lösung

a) Erweiterung der Kenntnis saharischer Pluvialzeitspuren

b) Methoden der Altersbestimmung

c) Ausdehnung der Betrachtung auf das Pliozän

III) Abriß des pliozän-quartären Klimaganges in den betrachteten Breitenzonen

a) Mitteleuropäische Beckenlagen (thermischer und hygrischer Klimaablauf)

b) N-Saum der Sahara (Südfluß des Hohen-, des Anti- und Sahara-Atlas)

c) Nördl. Zentralzone der Sahara (Tademaït, Libyen, Ägypten)

d) Südl. Zentralzone der Sahara (Hoggargebirge)

e) S-Saum der Sahara (Senegal, Tschadseegebiet)

IV) Bedeutung des saharischen Klimaganges für die allgemeine Klimageschichte

a) Sonderstellung des Pleistozäns im ganzen, der Würmzeit im besonderen

b) „Polare" und „äquatoriale" Feuchtzeiten in der Sahara

c) Geologischer und klimatischer Aktualismus. Die „Alte Tropenerde“ (Eozän-Miozän)

d) Die Zonal-Differenzierung des Zirkulationssystems im Pliozän

e) Das Aufkommen meridionaler Zirkulationstypen und die Asymmetrie der der Sahara-Pluvialfolge im Pleistozän

1) Fortschreitende Gebirgshebungen im Quartär

2) Gang der Inlandeis-Bildung auf der Nordhalbkugel

3) Die schrittweise Absenkung der interglazial-eustatischen Ozeanstände

4) Der verzögerte Aufbau des Antarktischen Inlandeises. 


\section{I) Entwicklung des Problems}

Kaum hatten A. Penck und J. GeIKIE im Jahre 1882 die Gliederung des Eiszeitalters in mehrere Kaltzeiten (Glaziale) und zwischenliegende Warmzeiten (Interglaziale) nachgewiesen, als bald zwei wichtige Folgerungen gezogen wurden. Einmal erwies sich, daß diese 3- bis 5-fache Aufeinanderfolge sich im Abstand von rd. $10^{5}$ Jahren in so auffallend ähnlicher Form wiederholender Vergletscherungen in fast allen Teilen der Außertropen und für die beiden letzten Kaltzeiten selbst für die meisten tropischen Hochgebirge galt. Zum zweiten zeigte sich in vielen Trockenräumen der tropischen Tiefländer, vor allem den tropisch-subtropischen Passatwüsten durch das Quartär eine ähnlich anmutende Folge von Feuchtzeiten, für die E. Hull in Palästina 1884 zum erstenmal das Wort „Pluvial“ anwandte (später durch den Ausdruck „Interpluvial“ für Trockenzeiten ergänzt). Aus dem gemeinsamen quartären Alter beider Erscheinungen und bestimmten meteorologischen Überlegungen lag es nahe, in diesen "Pluvialen“ die Wüstenausprägung oder die dorthin reichende Auswirkung der ektropischen „Glaziale“, in den „Interpluvialzeiten" solche der „Interglaziale“ zu erblicken.

Diese erste Arbeitshypothese bahnte den Weg zu weiteren Fragen. Die erste lautete: stimmen innerhalb des Quartär die Pluviale der Sahara zeitlich — und kausal — wirklich mit den Kaltzeiten der Ektropen ïberein? Die zweite: wenn ja, treten solche kaltzeitsynchronen Pluviale in allen Teilen der europagroßen Wüste gleichartig und gleichzeitig vom $\mathrm{N}$-Rand bis zum S-Saum auf?

A. Penck vertrat hier zunächst die Ansicht, daß die Passat-Trockengürtel in den Kaltzeiten als Ganzes äquatorwärts verschoben worden seien, d. h. also ihr Polarsaum zwar feuchter, ihr Aquatorialsaum aber trockener gewesen sei als heute. Das hätte eine Verschmälerung der äquatorialen Regenzone in jeder Kaltzeit bewirkt (mit der stillschweigenden Annahme einer umgekehrten Verschiebung in den Interglazialzeiten). Für ihn war dabei Schneegrenz-Depression in den Hochgebirgen mit Feuchtigkeitszunahme im darunter liegenden wüstenhaften Tropentiefland gekoppelt. Als weitere Forschungen nun ergaben, daß die eiszeitliche Schneegrenz-Depression (etwa in den Hochanden) über a $11 \mathrm{e}$ n Teilen der Passat-Trockengürtel ähnlich stark war, gab er seine erste Hypothese später auf und kennzeichnete auf der Wiener Quartär-Konferenz von 1936 seinen Standpunkt sinngemäß wie folgt: nicht die regenreichen Tropen waren während der Kaltzeit eingeengt, sondern die subtropischen Wüstengürtel der Passatzonen. Dies blieb-in der Folgezeit die Ansicht der meisten Geographen und Geologen, nicht aber der Prähistoriker. Von diesen hielten viele an der älteren Anschauung fest. Sie wurde eine halbe Generation später von L. BALOUT (1952) für die französische Sahara dahin präzisiert, daß es in der Sahara zweierlei Arten pleistozäner Pluvialzeiten gäbe: „etesische“ an ihrem mittelmeerischen Nordsaum, die nur in den Kaltzeiten, und „monsunale“ am Südsaum, die nur in den pleistozänen Warmzeiten aufträten. Dies läuft, wie man sieht, im Kern auf die ältere PencK'sche Anschauung hinaus: Verschiebung der \pm ungeschmälerten Trockenzonen in jeder Kaltzeit zum Äquator hin, in jeder Warmzeit wieder polwärts zurück.

\section{II) Wege zur Lösung}

a) Erweiterung der Kenntnis saharischer Pluvialzeitspuren Eine solche ist seit dem 2 . Weltkrieg auf verschiedene Weise erfolgt. Wichtige solche Spuren sind fossile Täler mit einer Sohlenfüllung aus gut gerundeten Schottern (fossil häufig: Konglomeratdecken), die heute nicht mehr oder nur selten (episodisch) von Flüssen benutzt werden, so daß seitlich zuführende Trockenschuttkegel (Wüstenfanglomerate) oder gar Dünen die Wadisohlen verhüllen. Konglomeratbedeckte Terrassenfolgen solcher Flüsse erwiesen sich als Spuren mehrerer Feuchtzeiten. Mensching $(1958,1960)$ hat diese Methode auf die Trennung weiter, ineinandergeschachtelter Gebirgsfußflächen (Pedimente) er- 
weitert. Im Mündungsbereich leiten Wadi-Terrassen oft zu solchen von abflußlosen Seen mit einst höher gespanntem Spiegel über. Fluviatile, lakustre und äolische Sedimente bergen oft tierische oder pflanzliche Fossilien, die Schlüsse auf ein ehedem feuchteres Klima zulassen (als sichere Zeugen für ein ehemals anderes Temperaturklima sind sie dagegen in der heißen Zone nur selten brauchbar). Dagegen konnte KNETSCH (1962) zeigen, daß die fossilen Grundwasservorräte der Sahara altersmäßig besonders gut faßbare Reste von Pluvialen sein können. Eine weitere Gruppe solcher Zeugen bilden fossile Böden, besonders Braunlehme, Rotlehme und Roterden (BüDEL, KubIENA 1955, FLINT, 1963), wogegen fossile Krustenböden (Eisenkrusten, Laterite, Kalk- und Gipskrusten) je nach ihrer Lage im Vergleich zu den heutigen Klimagürteln trockenere oder feuchtere Perioden anzeigen können (KNetsch, 1950, Büdel, 1953, Mensching 1955 u. a.), so daß für die klimageschichtliche Auswertung von Krusten - ja auch schon zur Bestimmung ihres Fossilitätsgrades überhaupt - besondere Sorgfalt nötig ist. A $11 \mathrm{e}$ fossilen Bodendecken erlauben im übrigen eine volle klimageschichtliche Auswertung nur in Verbindung mit der morphgenetischen Analyse der Flächen (Reliefgenerationen), denen sie zugehören, sowie aller geologischen Begleitumstände, sedimentärer wie plutonischer.Außerdem zeigen die meisten rezenten und fossilen Bodenprofile der Tropen wegen ihres meist hohen Alters in sich einen polygenetischen Aufbau (Kubiena 1962, 1963), dessen Parallelisierung mit der morphogenetischen Stellung der Auflagefläche das optimale Ziel solcher Untersuchungen ist. Denn jede Altersbestimmung irgendeiner Pluvialzeitspur hat in diesem Zusammenhang nur dann einen Sinn, wenn klargestellt ist, ob das betreffende Sediment wirklich exakt den Schluß auf feuchteres (oder trockeneres oder nur sonstwie andersartiges) Klima während der Entstehungszeit zuläßt.

\section{b) Methoden der Altersbestimmung}

Erwünscht ist natürlich für solche Parallelisierungen die absolute. Aber wir legen Wert auf die Feststellung, daß eine solche - etwa nach modernen Rechen- und physikalischen Labortmethoden - ohne eine vorhergehende, allseits abgesicherte relative Datierung im Gelände aufgrund der logisch-historischen Indizienketten, deren sich Geomorphlogie, Geologie und Vorgeschichte in ähnlicher Weise bedienen, nutzlos, ja irreführend sein kann. Eine Probe absolut-physikalischen Altersbestimmungen $\mathrm{zu}$ unterwerfen hat nur einen Sinn, wenn der klimageschichtliche Aussagewert, seine repräsentative Gültigkeit für ein weiteres Gebiet und die geologische Stellung des betreffenden Sediments vorher einwandfrei geklärt werden konnte. Bei der relativen Altersbestimmung ist es wichtig, möglichst Anfang und Ende der betreffenden Sedimentationsperiode (etwa einer Feuchtzeit) getrennt festzulegen, um ein erstes Maß für ihre Dauer zu erhalten. Nicht selten kann man wenigstens einen dieser Werte - meist das Ende - genauer festlegen. Schon das ist für Synchronisierungen von Vorteil.

Die Altersbestimmung durch pflanzliche Reste (etwa Pollenanalyse) scheidet in der Wüste weithin aus $\left.{ }^{1}\right)$. Auch die Succession der Faunen ist hier - in der Nähe der in den Tropen ja fortdauernden "Alten Tropenerde“ - für die aufeinanderfolgenden Pleistozänabschnitte nicht so kennzeichnend wie bei uns. Um so größer ist die Bedeutung der prähistorischen Werkzeuge des Menschen. Im Holozän - etwa Ägyptens - reicht endlich die genau datierbare Schriftgeschichte rd. 3500 Jahre weiter zurück als in Mitteleuropa (Butzer, 1958, 1959; Wright jr., 1961 u. a.). In den Atlasländern wie in Ägypten und anderwärts gelang die Parallelisierung von Pluvial- und Interpluvialspuren mit den um die Küsten der ganzen Erde verknüpfbaren eustatischen Terrassen der pleistozänen Warmzeiten (Mensching 1953-1957, Pfannenstiel, 1953, Choubert, 1957, Butzer und

1) Eine Ausnahme machen Wüstengebirge (Hoggar, Tibesti), vgl. die neueren Untersuchungen von Quézel und Martinez (1962) sowie von van Zinderen-BaKter (1962, 1963), die mir erst während der Drucklegung dieses Aufsatzes zugänglich wurden. 
Cuerda, 1962 u. a.). „Exakte“ Zeitbestimmungen wie Radiokarbondatierungen sind hier bis jetzt erst in wenigen Fällen in überzeugender Weise angewandt worden; mit den letzteren können bislang nur die letzten 50000 Jahre erfaßt werden.

c) A usdehnung der Betrachtung a uf das Pliozän

Das Holozän schließt sich eng an die eiszeitliche Klimageschichte an. Seine Bedeutung liegt hierbei darin, daß wir nur für die Gegenwart (im engsten Sinne) die allgemeine Zirkulation der Atmosphäre genau kennen. So geht die meteorologische Ana1 y s e des Eiszeitklimas stets vom Holozän aus. Das eiszeitliche Klima stellt sich von hier aus gesehen in allen seinen Zügen nur als graduell verschiedene Abwand$1 \mathrm{u} n \mathrm{~g}$ des Gegenwartsklimas dar. Indessen war die genetische Ausgangsbasis für zahlreiche klimabestimmende Faktoren des Pleistozän nicht deren holozäner Entwicklungsstand, sondern derjenige des $\mathrm{Oberpliozän}$. Das gilt von der damaligen Verteilung von Meer und Land, der Höhe der Gebirge, dem Vorhandensein oder Fehlen großer Vergletscherungen, der Lage der Pole, der ererbten Bodendecke weiter Räume und vielen anderen Zügen. Selbst bei der - unwahrscheinlichen - Annahme einer völlig gleichen Sonnenzustrahlung mußte die Abwandlung dieser „terrestrischen Klimafaktoren“ dem Klima des Oberpliozän und in seiner Weiterentwicklung auch dem des Pleistozän Züge verleihen, die von denen des Holozän deutlich abwichen. Das Bild des eiszeitlichen Klimaganges muß daher durch denjenigen des Pliozän ergänzt werden, der zu jenem führt.

\section{III) Abriß des pliozän-quartären Klimaganges in den betrachteten Breitenzonen}

Abb. 1 stellt dementsprechend den Klimaablauf seit der Mio-Pliozänwende, d. h. in den letzten 10-12 Mill. Jahren dar. Er beruht auf einer entsprechenden Auswertung der erdwissenschaftlichen Klimazeugen und beschränkt sich dabei auf die Angabe, ob man danach das Klima der einzelnen Zeitabschnitte im Vergleich zur Gegenwart nach Feuchtigkeit (jeweils Spalte I) und Temperatur (Spalte II) als deut lich abweichend an-

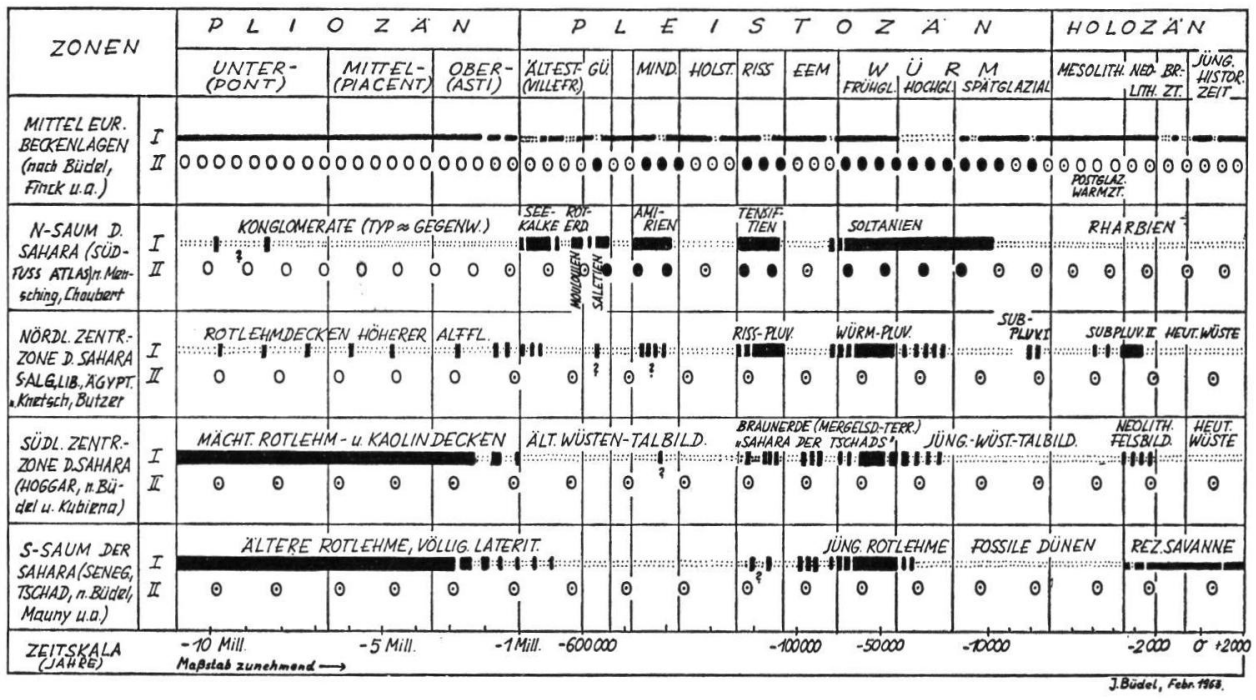

$I=$ FEUCHTIGKEIT:
II $=$ TEMPERATUR:

Abb. 1. Pliozäne und quartäre Kalt- und Feuchtzeiten in Mitteleuropa und in der Sahara. 
nehmen muß oder nicht. In Spalte I bedeutet dabei ein dicker Querbalken: wesentlich feuchter als heute, ein dünner: gleich feucht oder nur wenig feuchter als die Gegenwart, das doppelte Punktband: trockener als die Gegenwart. Die Signaturen zu den Spalten II sind unten auf Abb. 1 hinreichend erklärt.

Besonders für die älteren Zeiten sind die erhaltenen Spuren sehr lückenhaft. Die Darstellung für das Pliozän, das Ältest- und das Altpleistozän bietet daher nur eine summarische Pauschalangabe. Aus Gründen der Gleichmäßigkeit wurden dieselben Signaturen auch für die jüngeren Zeiten beibehalten. Daß für das Würmglazial und das Holozän natürlich weit genauere Angaben möglich wären, haben wir nur so weit berücksichtigt, als es die Wahl eines zunehmenden Zeitmaßstabes in dieser Richtung erlaubte.

Die Klimaentwicklung der Sahara ist in Abb. 1 für vier von $N$ nach S folgende Breitenzonen dargestellt, außerhalb zum Vergleich in der obersten Spalte diejenige für Mitteleuropa ("mitteleuropäische Beckenlagen“) als dem nächsten und am besten untersuchten ektropischen Nachbarraum. Für die Sahara ist eine Breiten-Zonierung als Grundlage einer solchen Untersuchung mehr als irgendwo berechtigt; wir befinden uns hier im Mustergebiet zonaler Anordnung der heutigen Klimagürtel. Die Meeresgrenzen im N und S laufen ebenso wie die begrenzenden Gebirge (Atlas und Oberguineaschwelle) fast genau westöstlich. Endlich setzt sich dieser Wüstenraum mit einer nur leicht nach ONO abbiegenden Achse nach Arabien und Iran fort.

\section{a) Mitteleuropäische Beckenlagen (thermischer und hygrischer Klimaablauf)}

Im Alttertiär (40-60 Millionen Tahre vor der Gegenwart) blühten auf Spitzbergen Walnüsse und Magnolien, tropisches Klima reichte bis in mittlere, subtropisches bis in heute polare Breiten. Dieser Zustand der "Alten Tropenerde" (BüDEL, 1962) hatte sich bis ins Obermiozän thermisch nur wenig verändert, wenngleich feuchtere mit trockenen Perioden wechselten; deutliche Trockenperioden zeigt in Mitteleuropa u. a. das Helvet (Mittel-Miozän. Rutte, 1963) und das Sarmat (oberstes Miozän), besonders dessen mittlerer Abschnitt (W INkr,F.R, 1960. Schwarzbach, 1961). In dem langen, schmalen, nur nach O sich etwas breiter öffnenden Meeresarm des Alpenvorlandes im Burdigal (höheres Altmiozän) zeigt die $200 \mathrm{~km}$ lange. bis $70 \mathrm{~m}$ hohe Klifflinie am SO-Saum der Schwäbischen Alb (Gtaser, 1963) die Vorherrschaft von Ostwinden im damaligen Mitteleuropa an. Das gleiche bezeugen die breiten Strandterrassen und hohen Kliffs des Tortonmeeres und des unternliozänen (pontischen) Binnensees am Alpenrand des Wiener Beckens im harten Dachsteinkalk. Das Klima des Unterpliozän (Pont) mit seinen reichen Kohlenlagern war (gegenüber dem Sarmat) wieder feuchter. Das Temperaturniveau Mitteleuropas lag gegenüber dem Alttertiär schon deutlich niedriger, hielt sich aber auch damals - vor etwa 10-12 Tahrmillionen - noch auf einem randtropisch-subtropischen Stand.

Von diesem aus erfolgte im Mittel- und Oberpliozän eine weitere langsame Abkühlung: ein weiterer äquatorwärtiger Rückzug der "Alten Tropenerde“. Der Grad dieser Absenkung bis an die Schwelle des Pleistozän (vor 1 Jahrmillion) ist umstritten. Fest steht nur. daß er noch geringfügig war im Vergleich mit dem rascheren Temperaturabfall, der sich im Ältestpleistozän (Kalabrien, Villafranca) ankündigte und erst recht gegenüber dem Klimasturz Mitteleuropas in polare Verhältnisse, der dann mit der ersten echten Kaltzeit (Donau- bzw. Prägünz-Kaltzeit) vor etwa 600000 Jahren eintrat. Die Entwicklung der Tier- und Pflanzenwelt Mitteleuropas im Pliozän zeigt schon wegen der zeitlichen Nähe eine zunehmende Annäherung an die heutigen Formen. Aber es ist ungewiß, wieweit für diese Entwicklung gerade der eine Faktor der Senkung der mittleren Jahrestemperatur und wieweit andere Einflüsse auf die Phylogenie maßgebend waren. Nur wenige Gattungen und Arten haben schließlich die letzte Anpassung an das pleistozäne 
Kaltklima vollziehen können. Viele, oft nahe verwandte Typen mit engerer Wärmeanpassung sind mit dieser Klimawende - rascher oder langsamer - ausgestorben. Aus ihrer vorher, noch im Lauf des Pliozän erfolgten Annäherung an die heutigen Typen kann man nicht ohne weiteres auf eine ebenso große Annäherung der pliozänen Temperaturentwicklung an die pleistozäne schließen. Aus diesem Grunde dürften die von Schwarzbach (1961, S. 149) nach verschiedenen Autoren aus der Annäherung pliozäner Floren und Faunen an die Gegenwart zusammengestellten Wärmegrade für das Tertiär eher zu niedrig als zu hoch liegen. Immerhin wäre selbst dann der Wandel vom Oberoligozän $\left(18^{\circ}\right)$ über das Miozän $\left(16^{\circ}\right)$ zum Pliozän $\left(14^{\circ}\right)$ noch geringer, als der Sturz von letzteren auf das warmzeitliche $\left(9^{\circ}\right)$ oder gar das kaltzeitliche Pleistozänniveau $\left(0^{\circ}\right)$. Typische Polar- und Hochgebirgsfaunen (etwa mit Ren, Lemming, Gemse) sind dem gesamten Pliozän auf jeden Fall noch völlig fremd, sie entstehen erst allmählich im Lauf des Pleistozän (Sickenberg, 1951).

Sicherere Hinweise bieten anorganische Klimazeugen. Vier Umstände erscheinen dabei wichtig. Der erste: wir finden auf der Erde bis zum Ausgang des Oberpliozän k e in e Anzeichen für die Existenz inlandeisbedeckter Polarkalotten und auch kaum solche für vergletscherte Hochgebirge (SchwarzBach, 1961, S. 156-158). Der zweite: die oberpliozänen Basalte der Oststeiermark sind $\mathrm{n}$ a $\mathrm{ch}$ ihrer in der Mitte dieses Zeitraums (zwischen Daz und Levantin) erfolgten Ausbruchsphase noch von einer $15 \mathrm{~m}$ tiefen Rotlehmverwitterung feuchtsubtropischen Charakters überdeckt worden (WINKLER, 1957, S. 678 und 735); ein bedeutsamer Klimawechsel erfolgte erst vom Asti zum Kalabrien (S. 323). Der dritte: in vielen Teilen Mitteleuropas wurden noch im Oberpliozän ausgedehnte Verebnungsflächen ganz nach Art der wechselfeucht-tropischen bis subtropischen angelegt, die noch rücksichtslos über viele Gesteinsunterschiede und die Wasserscheiden der erst später - im Pleistozän - in Talgefäße eingeschnittenen Flüsse hinweggreifen. Meine Beobachtungen aus dem fränkischen Gäuland (BüDEL, 1957) wurden von denen vieler anderer Autoren, so insbesondere MENSCHING (1957) für die Rhön, WiNkLER (1957) und Fink (1961) für die Ostabdachung des Böhmischen Massivs und der Ostalpen bestätigt. Der vierte: subtropische Rotlehmbildung und subtropische Formbildungsvorgänge (Fußflächenbildung) können noch herrschen, wenn die Winter schon kalt, aber die Sommertemperaturen n o ch hoch sind und mit einer Sommer-Regenzeit zusammenfallen („monsunale“ Subtropen). Neben trocken-kalten Wintern bleiben dann die feucht-heißen Sommer immer noch die bodenkundlich und morphologisch "aktive“ Jahreszeit. Für eine an Dauerwärme angepaßte Biosphäre bedeuten jedoch kalte Winter schon eine scharfe Auslese. Wenn also im Laufe des Pliozän tropische Floren- und Faunenelemente zurück- und „mitteleuropäische" hervortreten, so braucht man daraus noch nicht auf einen gleich starken Wandel der anorganischen Vorgänge zu schließen.

Erst mit dem Villafranca waren infolge vermehrter mechanischer Verwitterung und der Zunahme grober Erosionswerkzeuge die mitteleuropäischen Flüsse zu stärkeren Ansätzen der Talbildung in überbreiten, noch wenig in die Rumpfflächen eingetieften Tälern imstande. Diese ganz entscheidende Umstellung der morphogenetischen Prozesse - erste Talbildung nach vielen Jahrmillionen vorherrschender Flächenbildung in den mitteleuropäischen Becken- und Mittelgebirgslagen - war aber erst von einer bescheidenen weiteren Abkühlung begleitet. Alle Anzeichen weisen vielmehr darauf hin, daß hier im Altestpleistozän das Klima zunächst einmal gegenüber dem noch feuchten Oberpliozän deutlich trocken e r wurde. Auf entsprechenden Terrassen des Maintales fand Körber (1963) Windkanter mit Wüstenlack, ähnliche Beobachtungen hat BAKKeR (1938) aus Westeuropa mitgeteilt. Nach den Faunen gliedert sich das Altestpleistozän in Mitteleuropa in eine ältere Savannen- oder Steppenzeit, eine mittlere Waldzeit und eine jüngere Steppenzeit. Ein deutlicher Umschlag auch in der Biosphäre ist das Auftreten vieler Großsäuger (WILHELMY, 1958).

Die eigentliche thermische Klimawende erfolgte dann mit dem Einsetzen der ersten 
Kaltzeit (auf die Darstellung von Prägünz-Kaltzeiten sowie der mutmaßlichen Zweiteilung der Mindel- und Riß--Kaltzeit - vgl. Graul, 1962 - wurde aus Maßstabgründen in Abb. 1 verzichtet). Sämtliche weiteren Kaltzeiten zeigen einen ähnlichen Verlauf: einen relativ raschen Temperaturabfall um rd. $8^{\circ}$ in der freien Atmosphäre (und rd. das Doppelte in Bodennähe der mitteleuropäischen Beckenlagen) sowie einen ähnlich raschen Wiederanstieg auf ein annähernd dem Holozän entsprechendes Temperaturniveau in den zwischenliegenden Warmzeiten. Das jeweilige Hochglazial führt zugleich zu einer ausgesprochenen Trockenphase (Lößzeit: Lößtundra und Lößsteppe). Die Würmzeit ist - heute mit mehr Recht als je - als eine nur von sekundären Interstadialschwankungen begleitete einheitliche Klimawelle dargestellt (BüDEL, 1960, FINK, 1962), der die wohlbekannten kleineren Klimawellen der Spät- und Postglazialzeit in maßstabgerechter Vereinfachung folgen.

b) N-Saum der Sahara ( $\mathrm{Südfußdes} \mathrm{Hohen,} \mathrm{des} \mathrm{Anti-}$ und des Sahara-Atlas)

In der heutigen pflanzengeographischen Zone der Wüstensteppe am Sahara-Nordsaum hatten KNETSCH (1950) in Libyen und BüDEL (1952) in Südalgerien aus der Verknüpfung von Flußterrassen mit Kalkkrusten- und Karstgenerationen eine Folge von 5 durch Trokkenphasen unterbrochenen quartären Feuchtzeiten festgestellt, von denen die älteste mutmaßlich ältestpleistozäne - die stärkste war. Dies Ergebnis wurde durch die schon genannten Untersuchungen von Mensching $(1955,1960)$ und Choubert (1957) durch die genaue Trennung von 6 Pluvialzeiten (Seekalkzeit, Moulouyen, Saletien, Amerien, Tensiftien, Soltanien) und deren exakte Parallelisierung mit zwei Prägünz-Kaltzeiten sowie der Günz-, Mindel-, Riß- und Würmkaltzeit gefestigt. Dies gelang insbesondere MENSCHING durch die Verknüpfung der entsprechenden weiten Pedimentfluren mit den Moränen des Hohen Atlas (für Riß und Würm) als auch diejenige der interglazial-interpluvialen Zwischenphasen mit den entsprechenden eustatischen Meeresterrassen sowie durch die Eingliederung dieser Klimaphasen in die prähistorischen Stufen. Für diesen Raum ist somit die Gleichzeitigkeit aller fünf bis sechs ektropischen Kaltzeiten des Pleistozän mit der gleichen Zahl saharischer Pluvialzeiten wohl gesichert. Das Kaltzeitphänomen erfaßte jeweils die ganze anschließende Polarkalotte, die entsprechenden Pluvialzeiten nur einen kleinen Nachbarraum. Bei so gleichartiger Wiederholung desselben Zusammenklangs scheint der Schluß berechtigt: diese Pluvialzeiten am Südsaum des Maghreb wurden das ganze Pleistozän hindurch von den außertropischen Kaltzeiten gesteuert, sie hängen kausal von den „Eiszeiten“ ab. Diese Folgerung wird noch durch den Umkehrbeweis gestärkt, daß sich weder nachher noch vorher: weder für das Holozän und vor allem nicht für die vorausgehende lange Pliozänzeit - mindestens deren jüngere Abschnitte - hier irgendwelche stärkeren Feuchtzeitspuren bisher nachweisen ließen ${ }^{2}$ ). Das erhärtet für diese Zone das Ergebnis: ohne (außertropische) Kaltzeit keine (nordsaharische) Feuchtzeit. In den letzten 5-10 Jahrmillionen scheinen hier in der Tat - mindestens ganz vorwiegend von den Außertropen her wirksame thermische und Zirkulationsschwankungen das Auftreten von Pluvialzeiten bewirkt zu haben.

\section{c) Nördliche Zentralzone der Sahara (Tademaït, Libyen, Ägypten)}

Aber schon in dieser Zone (Südalgerien, Libyen und Ägypten, etwa zwischen $25^{\circ}$ und $30^{\circ} \mathrm{NBr}$.) ändert sich das Bild. Von den fünf bis sechs pleistozänen Kaltzeiten der Ektro-

2) Erst für das Miozän lassen sich hier (nach freundlicher mündlicher Mitteilung von H. Mensching am 2. 2. 1963) Spuren einer älteren großen Feuchtzeit nachweisen. Vielleicht kann man in Analogie zu Nachbargebieten annehmen, daß diese miozäne Feuchtzeit noch etwas ins tiefste Pliozän hineinreichte (mit Fragezeichen in Abb. 1 angedeutet). 
pen sind hier nur die beiden letzten: Würm- und Rißkaltzeit durch parallele Pluvialzeiten vertreten. Am exaktesten gelang hier KNETSCH (1963) im Grenzraum zwischen Libyen und Ägypten der Nachweis für ein sehr kräftiges Würm-Pluvial, denn er konnte mit der Radiokarbon-Methode nachweisen, daß die reichen fossilen Grundwasservorräte unter den westägyptischen Oasendepressionen ein Alter von 25-45 000 Jahren besitzen. Deutliche Spuren einer vermutlich gleichfalls würmzeitlichen Feuchtzeit zeigt die charakteristische Mergelsandterrasse des Wadi Feiran auf Sinai (BüDEL, 1954). Im Umkreis des ägyptischen Niltales konnte Butzer (1958) mit guten Gründen ein Riß-neben diesem Würmpluvial belegen. Von einer Mindel-Pluvialzeit gibt es aber nur noch sehr fragliche Spuren (Butzer, 1958, S. 102). Schwache Rotlehmspuren auf Kalksanden der dem Sizil entsprechenden Nilterrassen verlegt Butzer (1959, S. 66) allgemein ins „Prä-Mindel“. Anzeichen älterer Pluvialzeiten gibt es somit auch noch in Ägypten, aber ihre Parallelität mit den entsprechenden Kaltzeiten der Außertropen ist zumindest unsicher und keinesfalls mehr zwingend. Ganz allgemein herrscht dagegen der Eindruck, daß das Klima Agyptens von der (eine oberpliozäne Feuchtphase abschließenden) Plio-Pleistozänwende an bis zu den jüngsten Feuchtzeiten des Riß- und Würmpluvials immer trockener wurde (PFAnNenstiel, 1955).

In Übereinstimmung damit zeigen sich auch im Zentral- und Westteil dieser Zone die Spuren älterer, präpleistozäner Feuchtzeiten. In der westlichen Sahara konnte weder ich selbst (1951) noch später MEcKeLEIN (1954) altpleistozäne Feuchtzeitspuren finden. Wohl aber sind dort hochgelegene Altflächen, wie das große Kreideplateau von Tademaït (27 bis $30^{\circ} \mathrm{NBr}$., rd. $600 \mathrm{~m}$ Seehöhe) allein in der N-S-Erstreckung auf mehrere hundert km unter dem rezenten Wüstenpflaster von einer ausgedehnten fossilen Rotlehmdecke verhüllt, aus der durch Wind- und gelegentliche Spülflutabtragung das heutige Pflaster entstand. Charakter, Ausdehnung und Höhenlage der Tademaït-Rotlehmdecke deutet entschieden auf eine sehr lange präpleistozäne Feuchtzeit aus dem Jungtertiär hin, die vom Pliozän möglicherweise noch in das Altestpleistozän hineinreichte, wie es Abb. 1 andeutet (BüDEL, 1951). Ganz ähnliche Rotlehme auf entsprechenden Altflächen fand MEckelein (1959, S. 95, 129, 165) unter $28^{\circ}$ bzw. $25^{\circ} \mathrm{NBr}$. auf dem Basaltplateau des „Djebel es-Soda“ (Fezzan) auf einer $600 \mathrm{~m}$ hohen Altfläche und auf den kleinen Plateaus von Graret Tebu am Nordsaum des Serir Tibesti in ähnlicher Lage. Er sowie Kubiena $(1957,1959)$, der diese Böden untersuchte, stellten sie in eine „jungtertiäre Feuchtzeit“. Damit stimmen die Reste "tertiärer Seen“ überein, die LEFrANC (1957) in der östlichen Hofra-Senke fand, sowie vor allem die von PFAnNenstiel (1953, S. 375-379) durch eine ausgedehnte geologische Literatur belegte Phase „oberpliozäner Flußtätigkeit“ in Oberägyvten. Diese einstigen Nebenflüsse des Nil führten Sand und Blockwerk, auch ihre Talstufen lassen auf periodisch-episodischen Lauf in einem halbtrockenen Klima schließen. Nach Pfannenstiel reichte diese Flußtätigkeit (mit Nachklängen) noch bis ins älteste Pleistozän, dann wurde das Klima immer trockener, die alten Talnetze von Dünen überschüttet, wie man es in diese Breitenzone auch in der westlichen Sahara (an der Tademaït-Stufe wie bei El Golea in offensichtlich alten Wüstentälern) vielfach beobachten kann.

Zum erstenmal begegnen wir schließlich in dieser Breitenzone auch bereits holozänen Pluvialzeiten. Butzen (s. o.) hat sie als „Subpluvial I“ und „Subpluvial II“ der jüngeren Tundrenzeit (also den letzten Kaltzeitrückfall der mitteleuropäischen Ektropen) bzw. dem späteren Mesolithikum und vor allem dem Neolithikum (und damit hier der ektropischen „Postglazialen Wärmezeit“!) zugeordnet. Das letztere ist ein zunächst auffallendes Phänomen, dem wir aber in der südlichen Sahara verstärkt begegnen werden. So kann man zusammenfassend nach dem heutigen Forschungsstand von dieser Zone sagen: es sind noch recht deutliche Anklänge an die - außertropisch gesteuerten - NordsaumFeuchtzeiten vorhanden, im ganzen aber überwiegend bereits diejenigen an die südsaharischen Verhältnisse. 
d) Südliche Zentralzoneder Sahara

(Hoggar-Gebirge)

Der letztgenannte Typus der Pluvialzeitenfolge beherrscht schon die südliche Zentralzon e der Sahara. Das mitten in diesem Breitenbereich (rd. 20-25 $5^{\circ} \mathrm{NBr}$.) gelegene Hoggar-Massiv zeigt dies besonders klar (BüDEL, 1952, 1955; KubIENA, 1955). Allein auf der SW-Flanke des Gebirges sind die beherrschenden Altflächen zwischen 1500 und $2400 \mathrm{~m}$ auf einer Fläche von mindestens $200 \mathrm{~km}^{2}$ mit bis über $20 \mathrm{~m}$ mächtigen Lagen tiefgründiger Kaolinverwitterung bedeckt. Diese alten Böden sind nur unter den sog. „altbasaltischen Lavaergüssen“ erhalten, die ihrerseits Tausende von $\mathrm{km}^{2}$ bedecken; die mächtigen kaolinreichen Rot- und Weißlehme unter diesen Basalten dürften somit ebenfalls noch ein weit größeres Areal überziehen, als es in den genannten $200 \mathrm{~km}^{2}$ erschlossen ist. Die unter diesen Lavaergüssen verhüllte, einen altgepreßten Kristallinsockel trotz aller Gesteinsunterschiede rücksichtslos kappende und durch die genannte Kaolinverwitterung gekennzeichnete Rumpffläche erfordert eine Herrschaft relativer tektonischer Ruhe und zugleich tropisch-wechselfeuchten Klimas während einer geologischen Periode von mindestens $10^{7}$ Jahren. Das ganze Pliozän reicht dazu kaum aus, der Beginn dieser Periode kann daher bis ins Mittel- und Alttertiär zurückreichen. Es handelt sich hier um die eindeutige Spur der tropisch-randtropisch-wechselfeuchten „Alten Tropencrde“, die in der Tertiärzeit bis tief ins Pliozän hinein einen viel größeren Teil der Welt (polwärts bis in die Breiten von Mitteleuropa und Südskandinavien) beherrschte als heute. Es war eine lange große Warmzeit, erst gegen ihr Ende, mit dem Ausgang des Pliozän und dem Übergang zum Pleistozän treten auf der Erde wieder vereiste Polarkalotten und vergletscherte Hochgebirge auf (SCHWARzBACH, 1961). Innerhalb dieser alten Warmzeit wechselten trockenere und feuchtere Perioden zeitlich und räumlich miteinander $\mathrm{ab}$. Im ganzen aber herrschte jedenfalls im Hoggar-Gebirge, im Plateau von Tademaït und in den genannten Bereichen Libyens, kurz in großen Teilen gerade der heutigen Zentralen und Südlichen Sahara im Miozän und danach noch durch lange Perioden des Pliozän kein trockenes, sondern ein warm-wechselfeuchtes Savannenklima (Kubiena, 1955). Der Feuchtzeitenverlauf ist also hier annähernd umgekehrt wie am Sahara-N-Saum: dort herrschte vor dem Pleistozän (wenigstens im jüngeren und mittleren Pliozän) sowie danach, im Holozän weithin das heutige Trockenklima, das Pleistozän aber bringt dorthin Feuchtzeiten parallel mit den außertropischen Kaltzeiten. Im Hoggar herrscht umgekehrt bis an die Schwelle des Pleistozän das wechselfeuchte Savannenklima der „Alten Tropenerde“; mit dem Einsetzen des Pleistozän aber beginnt die Trockenperiode mit der Entwicklung der Wüstenmorphologie, die bis heute die Zertalung des Gebirges beherrscht. Dieser Ablauf wird nur durch e ine deutliche Feuchtzeit unterbrochen, die ins jüngere Pleistozän einzuordnen ist (BüDEI, und KUBIENA, 1955). Ihre weite Verbreitung ist durch ihr völlig analoges Auftreten im Hochgebirge von Sinai gesichert (BüDEL, 1956), sie entspricht wahrscheinlich der von französischen Archäologen und Paläontologen an zahlreichen Stellen der großen Wüste nachgewiesenen „Sahara der Tschads“. Ganz schwach - nur mit biogeographischen Sekundärspuren, aber ohne einen zugehörigen Formenschatz mit Fossilböden - ist danach noch eine holozäne Feuchtzeit im Hoggar angedeutet, der auch die reiche (sudanische) Jagdtierwelt der älteren (neolithischen) Felsbilder angehört (BüDEL 1952, 1955, SchWARzbach 1953).

\section{e) Süds a um der S a h a r a (Senegal, Tschadseegebiet)}

Eine Bestätigung der im Hoggar und in Südlibyen aus morphologischen und bodenkundlichen Spuren abgeleiteten Pluvialzeitfolge liegt darin, daß am S üds a um der $\mathrm{S}$ a har a (etwa zwischen 14 und $20^{\circ} \mathrm{NBr}$.), im Grenzgebiet zum heutigen, tropischwechselfeuchten („monsunalen“) Sudan-Klima praktisch dieselbe Feuchtzeitfolge auftritt. Nur sind hier die abweichenden Akzente gegenüber dem Nordsaum noch stärker. Die 
"Alte Tropenerde" wird etwa auf der kapverdischen Halbinsel und im Westen der senegambischen Platte durch die mächtige basale Eisenkruste des heutigen Bodenprofils repräsentiert, wie sie z. B. in der Umgebung von Dakar in zahlreichen Aufschlüssen als Werkstein ausgebeutet wird. Am meerwärtigen Abbruch der senegambischen Platte bildet diese Kruste die harte Bank, an die sich die $50 \mathrm{~m}$ hohe Schichtstufe dieses Abfalles knüpft (BüDEL, 1952). Selbst wenn man für die Abtragung eines so hohen Stufenrandes die kürzestmögliche Zeitspanne ansetzt, so reicht die Bildung dieser Kruste doch sicher vor das Pleistozän zurück. Es ist eine sehr alte, heute völlig lateritisierte und verkrustete Rotlehmdecke. Auf sie folgte - vermutlich im Alt- und Mittelpleistozän - eine längere Trockenperiode, über deren Spuren sich die „jüngere Rotlehmdecke“ mit geringerer Mächtigkeit und nur teilweiser brecciöser Verfestigung legt. In ihren obersten 10-12 cm und an ihrer Oberfläche finden sich zahlreiche Werkzeuge des oberen Moustérien (MAUnY, 1949). Die Feuchtzeit, in der diese Rotlehme gebildet wurden, umfaßt daher die frühe Würmkaltzeit, mag aber darüber hinaus noch bis ins Eem oder selbst ins Riß zurückreichen, ohne daß dabei eine genauere Parallelisierung mit der ektropischen Warm-Kaltzeitfolge möglich wäre. Im ganzen gibt es also auch hier nur e in e ausgeprägte jung-pleistozäne Feuchtzeit (entsprechend der "Sahara der 'Tschads").

Über diesen jüngeren Rotlehmen Senegambiens lagert nun ein aus dem Frühholozän stammender fossiler Dünengürtel. Sein Alter wird dadurch erwiesen, daß sich auf seiner rubifizierten Oberfläche zahlreiche neolithische Reste finden. Ein weiteres Zeichen seiner Jugend sind die geschlossenen Hohlformen, die dieser ausgedehnte Dünenzug auch unter seinem heutigen Savannenkleid überall zeigt. Es ist endlich derselbe subfossile Dünengürtel, der den Tschadsee abdämmt, und da dieser trotz seines Endseecharakters Süßwasser führt, kann seine Entstehung - und damit die des stauenden Dünendammes - erst wenige Jahrtausende zurückliegen. Das Delta des von SO kommenden Schari drängt diesen „wandernden" Endsee immer weiter nordwärts in das Dünengebiet hinein, wo seine Küstenregion in einem den Dünenrücken entsprechenden Netz von Inseln und Halbinseln vielfältig aufgegliedert ist. fast ohne Andeutungen für die Bildung einer Ausgleichsküste. Auch dies zeigt, daß der Tschadsee ein sehr junges Gebilde ist (BüDEL, 1952).

Wir haben damit schon die Ausdehnung dieses Dünengürtels angedeutet, der sich in $300 \mathrm{~km}$ Breite vom Senegal bis ins Tschadseegebiet - wenn auch mit Unterbrechungen über rd. $4000 \mathrm{~km}$ hin, davon unmittelbar bei und westlich des Tschadsees allein über volle $650 \mathrm{~km}$ Länge zusammenhängend west-östlich verfolgen läßt. Dieses fossile Dünenband zeigt, daß am ganzen Sahara-S-Saum in der ersten Hälfte des Holozän (insbesondere in der postglazialen Wärmezeit bis in die Anfänge des Neolithikums) ein noch wesentlich trockeneres Klima herrschte als heute. Die darauffolgende Zeit des Neolithikums, dessen Spuren wir auf diesen Dünen finden, bedeutet jedoch hier nicht ein kurzes, wenig ausgeprägtes Feuchtintervall („Subpluvial“) wie im Hoggar-Gebirge und in Ägypten, sondern den Umschwung zu einer a usgeprägten, das ganze Jungholozän bis heute umfassenden Feuchtphase! Denn in der Gegenwart wird dieser ganze Gürtel von einer dichten Dornsavanne mit Affenbrotbäumen und hochwüchsigen Akazienarten beherrscht. Diese Savanne schob sich seit dem Neolithikum bis zu $300 \mathrm{~km}$ weit über diesen fossilen Dünensaum gegen das Innere der Wüste vor; die regelmäßigen 3-4monatlichen Regenzeiten dieser Zone ermöglichen überall Rindernomadismus und stellenweise sogar schon Regenfeldbau. Tropische Rotlehme treten heute $300-400 \mathrm{~km}$ weiter südlich (bei 6-7monatiger Regenzeit) auf. In der Gegenwart erreicht daher der Humiditätsgrad dieser jungholozänen Feuchtzeit etwa die halbe Höhe der jungpleistozänen Pluvialzeit. Daß sie zeitweilig noch etwas fe uchter war als heute, machen die historischen und prähistorischen Spiegelschwankungen des Tschadsees wahrscheinlich: sie rückte dann größenordnungsmäßig wohl noch näher an das jungpleistozäne Pluvial heran (durch die Dicke des schwarzen Balkens in Abb. 1 rechts unten angedeutet). 
IV) Bedeutung des saharischen Klimaganges für die allgemeine Klimageschichte

a) Sonderstellung des Pleistozän im ganzen, der Würmzeit im besonderen

Nach den betrachteten Spuren stellt die Klimageschichte der Sahara im Pliozän und Quartär in der Tat im wesentlichen eine Folge von Feucht- und Trockenzeiten dar, nur am Nordsaum sind diese mit thermisch verschiedenen Perioden gekoppelt. Beim Gesamtüberblick über alle vier Zonen ergibt sich vielerlei:

1) Insgesamt tritt das Pleistozän in allen Zonen der Sahara als eine h y g r is c h a ndersartige Periode zwischen dem vorangehenden Pliozän und dem nachfolgenden Holozän auf. Aber diese Andersartigkeit gegenüber dem vor- und nachher $\mathrm{ke} \mathrm{h} \mathrm{r} \mathrm{t} \mathrm{sich}$ vom $\mathrm{N}$ z u m S u m. Am N-Saum der Wüste (und z. T. noch in der nördlichen Zentralzone) ist das Pleistozän durch das Auftreten mehrer rhythmischer Feuchtzeiten zwischen fast reinen Trockenperioden im Pliozän und Holozän gekennzeichnet. Am S-Saum (und z. T. schon in der südlichen Zentralzone) liegt dagegen das Pleistozän im ganzen als trockenere Periode zwischen ausgeprägten Feuchtzeiten davor und danach.

2) Eine Betrachtung der saharischen Pluviale im einzelnen zeigt folgendes Bild: am N-Saum sehen wir für das ganze Pleistozän - vom Prägünz bis zum Würm - eine Parallelität zwischen den dortigen Feuchtzeiten und den mitteleuropäischen Kaltzeiten; diese waren dabei offensichtlich der dynamische Motor. Mit jeder Zone, die wir weiter südwärts vorrücken, setzt diese Parallelität rd. um eine "Eiszeit “ s päter ein, bis wir endlich am Sahara-S-Saum nur noch die Spuren e in e r Pluvialzeit finden, die ins Jungpleistozän fällt. Damit lockert sich die am N-Saum noch recht klare Kausalbeziehung zu den außertropischen Kaltzeiten in doppeltem Sinne. Einmal finden wir hier für die vier älteren Kaltzeiten (2 Prägünz, Günz, Mindel) kein Pluvialäquivalent mehr vor. Zum zweiten ist auch das einzige, noch durch deutliche Spuren vertretene Pleistozänpluvial nicht mehr deckend mit einer bestimmten außertropischen Kaltzeit synchronisierbar: ihr Ende fällt mitten in die Würmzeit, während ihr Beginn unbestimmt ist: er kann ins Eem, ja bis ins Riß zurückreichen.

3) Daraus ergibt sich, daß die jüngere Anschauung A. Pencks: die Sahara sei während der Kaltzeiten im ganzen feuchter gewesen und durch gleichzeitiges Vordringen ihrer Feuchtgrenzen von drei Seiten her: vom mediterranen N-Saum, vom äquatorialen S-Saum und von der Höhen-Feuchtgrenze in den Gebirgen her (letzteres parallel mit der Schneegrenzdepression) eingeengt worden, $\mathrm{nur} f \mathrm{u} r \mathrm{die}$ W ü rm$\mathrm{kaltzeit} \mathrm{nachgew}$ iesen werden konnte (auch für diese nur mit der genannten Einschränkung). Dies ergaben schon unsere früheren Arbeiten aus Europa und Afrika. In den schematischen Darstellungen über die eiszeitliche Verschiebung der Klimagürtel aus jener Zeit (BüDEL, 1949, 1952), die dann in mehrere Gesamtdarstellungen des Eiszeitalters eingingen (so HACK, 1953; Woldstedt, 1954; Flint, 1957; W AGNER, 1960; Schwarzbach, 1961), habe ich daher dies Ergebnis stets bew uß a uf die W ü rm$\mathrm{kaltz}$ e it beschränkt. Es gilt nach unserer Kenntnis (s. o.) schon für die Rißeiszeit nur noch in sehr eingeschränktem Maß, und je weiter wir von da zur Mindel-, Günz- und Prägünzzeit zurückgehen, desto eindeutiger war ein Vordringen der randlichen Feuchtgürtel gegen die Wüste nur noch am N-Saum, aber nicht mehr im S zu beobachten: hier fehlen weitgehend gleichzeitige Pluvialzeitspuren.

Ich war vor 12 Jahren von der Realität dieses - negativen - Ergebnisses für die älteren Kaltzeiten noch nicht überzeugt. Das Nichtauffinden älterer Pluvialzeitspuren in südlichen Sahara könnte ja u. U. in der dortigen geringeren Dichte des Beobachtungsnetzes oder - bei immer weiterem Fortschreiten in die Vergangenheit - in der immer schlechteren Erhaltung solcher Spuren begründet liegen.

Gegen das erste Bedenken spricht, daß sich trotz vieler neuer Arbeiten zu diesem Thema das in Abb. 1 gebotene Gesamtbild seither in Bezug auf die Nichtexistenz älter- 
pleistozäner Pluvialzeiten am Sahara-S-Saum nicht verschoben hat. Dagegen wurden sämtliche Pluvialzeiten am N-Saum bestätigt; die Mehrzahl von ihnen konnte mit außertropischen Kaltzeiten synchronisiert werden: das gilt besonders für die Würmkaltzeit.

Gegen den zweiten Einwand sprechen folgende Überlegungen. Die Spuren auch der älteren Kaltzeiten sind am N-Saum der Sahara noch gut erhalten und vielfach gefunden worden. Am S-Rand klafft dagegen noch heute dieselbe Lücke altpleistozäner Feuchtzeitspuren wie vor 12 Jahren. Doch konnten dort die Spuren älterer, nämlich pliozäner Feuchtzeiten in eindeutiger Erhaltung und sehr allgemeiner Verbreitung nachgewiesen werden.

So halte ich unser Gesamtbild in den durch oben 1-3 gekennzeichneten Grundzügen für real. Die Übersicht in Abb. 1 kann heute jedenfalls mit viel weniger Fragezeichen entworfen werden, als es noch vor 12 Jahren möglich gewesen wäre. Sie scheint nach unserem heutigen Kenntnisstand soweit gesichert, daß sich ihre Veröffentlichung und die im folgenden daraus abgeleitete Synthese als Grundlage für weitere Forschungen empfahl.

4) Damit fällt auch auf die Ansicht von Balout (=Pencks ältere Auffassung: nicht Einengung, sondern äquatorwärtige Verschiebung der Passat-Wüstengürtel in jeder Kaltzeit) ein neues Licht. Denn bei aller Gegensätzlichkeit hatten doch PENCK (jüngere Auffassung) wie BAOLUT ihre Theorien darauf gegründet, daß der pleistozäne Kalt-WarmzeitWechsel in den ektropischen Erdkalotten der e rze ugende Motor für den PluvialInterpluvial-Wechsel in den randtropischen Passat-Trockengürteln sei. Dies aber trifft jetzt offensichtlich auch für BALouts These nicht mehr zu. Denn im ganzen Pleistozän fanden wir am Sahara-S-Saum nur noch die Spuren einer Feuchtzeit, die sich weder mit einem ektropischen Glazial noch einem Interglazial streng synchronisieren ließ, sondern vermutlich über mehrere solche Umbrüche während des Jungpleistozän hinweggreift. Dafür zeigten sich dort ausgedehnte Feuchtzeitspuren im Prä- und Postglazial, die sichtlich unabhängig vom ektropischen Motor des Kalt-Warmzeit-Wechsels waren. Hier liegt eine wichtige Frage, die sich aus dem neuen Bild ergibt. Doch bleibt es BaLouts Verdienst, zum erstenmal auf den unterschiedlichen Rhythmus pleistozäner Feuchtzeitspuren am N-und S-Saum der Sahara hingewiesen und damit die weitere Forschung angeregt zu haben.

b) „Polare“ und "äquatoriale“ Feuchtzeiten in der Sahara

Die Pluviale am N- und die am S-Saum der Sahara zeigen somit einen dynamisch verschiedenen Ursprung. Derjenige der nordsaharischen liegt im Ektropenbereich: in der mehrfachen krättigen Abkühlung der gesamten nordhemisphärischen Kalotte vom heutigen Subtropenbereich bis zum Pol während der Kaltzeiten. In den tropischen Hochländern war die gleichzeitige Abkühlung bekanntlich nur etwa halb so groß, in Bodennähe im tropischen Tiefland (besonders, wo dichte Savannen und Urwälder ungestört ausdauerten) noch geringer. Bei größerer Nähe zum ektropischen Aktionszentrum zeigten die Nordsaumpluviale andere Eigenschaften als die südlichen. Es sind kürzere, hygrisch schwächere, aber vor allem deutlich $\mathrm{k}$ ü h l e r e Feuchtzeiten mit kräftiger Herabdrückung der Schneeund Solifluktionsgrenze und noch weit stärkerer Depression der Strukturbodengrenze. „Die Trockenschuttzone in der Tiefe geht unmittelbar in die Frostschuttzone in der Höhe über“" (Büdel, 1952, S. 112; dgl. HövermanN, 1954, S. 110 und Meckelein, 1959, S. 94)33).

3) Hierbei ist aber - wie angedeutet - scharf zwischen der Untergrenze geschlossener Solifluktion (als Abtragungsphänomen am Hang, streng beschränkt auf die Zonen eines besonders feuchten Frostwechselklimas in der Höhe) und der von ö rtlichen $\mathrm{Strukturboden-}$ v o r k o m m e n (auf ebenen Flächenstücken, ohne inhärente Abtragungsleistung) zu unterscheiden. Nur die letzteren Bildungen reichen in der Sahara heute (und erst recht in den Kaltzeiten!) so tief herab, daß sie sich mit den (stets rein örtlich beschränkten) Wüsten-Texturbodenformen berühren und verschwistern. Diese, aus Trockenriß- und Salzbildungs-Polygonen bestehenden Wüsten-Texturformen treten bis in Meeresnähe herab auf. Ich fand sie bei Kosseïr am Roten Meer, in einem der trockensten Wüstengebiete der Erde, bis $50 \mathrm{~m}$ Seehöhe herabreichend. Sie sind n i e mit Solifluktionserscheinungen gekoppelt und in den Mittellagen der Wüstengebirge nicht immer eindeutig von den Froststrukturen der höheren Klimastufen zu trennen. 
Morphologisch ist die Ausweitung von Gebirgsfuß-Pedimenten für dièse Pluviale charakteristisch (Mensching, insbes. 1958). Bodenkundlich sind sie im 'Tiefland bei $>400-500 \mathrm{~mm}$ Niederschlag durch Terra-Rossa-Böden charakterisiert, bei geringeren Niederschlägen treten kalkreiche, z. T. lößartige Steppenböden auf, und in einer etwa zwischen knapp $300 \mathrm{~m}$ und knapp $100 \mathrm{~mm}$ Niederschlag liegenden Zone bei geeignetem anstehenden Substrat - je nach der Zusammensetzung - Kalk- oder Gipskrusten. In ihren äußersten Wüstenausläufern werden diese Pluviale daher durch Kalkkrusten (z. B. verkrustete Dünen) gekennzeichnet. Nirgends aber ließ ihr Klima Eisen-, Mangan- oder Bauxitkrusten entstehen.

Den meteorologischen Zusammenhang dieser Pluviale mit dem zirkumpolaren Kaltzeitklima hat Flons (1953) abgeleitet. Die tiefe Absenkung der Temperatur im Bereich der Polarkalotten und die nur $\mathrm{rd}$. halb so große im gesamten Tropenbereich bedeutete eine erhebliche Verstärkung des Temperaturgegensatzes Tropen-Polargebiete. Vor allem aber waren die letzteren von ihrer heutigen Lage über den Großteil der Mittelbreiten ausgedehnt: im Meridianfeld Mitteleuropas lag die polare Waldgrenze statt bei $69^{\circ} \mathrm{NBr}$. (heute) bei $45^{\circ}$. Daneben hatte sich auch die Lage der Polarfront und damit der maximalen Intensität des Wettergeschehens um $15-20^{\circ}$ äquatorwärts verlagert: von heute $45-50^{\circ}$ auf etwa $30^{\circ}$. Man darf dem hinzufügen, daß diese äquatorwärts vorgeschobenen Polarfrontgürtel auch gewaltig an Längenausdehnung gewannen (Breitenkreis bei $50^{\circ} \mathrm{N}: 26000 \mathrm{~km}$, bei $30^{\circ} \mathrm{N}$ : $35000 \mathrm{~km}$ am Äquator: $40000 \mathrm{~km}$ ). D. h.: dem äquatorialen Aktionsgürtel der größten Erwärmung standen jetzt $z$ w e i kaum minder lange Aktionsgürtel von Kaltluftfronten im heutigen Subtropenbereich gegenüber. Die Folge davon war eine Abschwächung der zonalen und eine Verstärkung der Meridionalzirkulation. Vor allem wurde der heutige, ganzjährig durchlaufende subtropische Hochdruckgürtel, an den die Existenz der „Passatwüsten“ geknüptt ist, durch häufige regenbringende Polarluftvorstöße in einzelne "Zellen“ aufgelöst. Die stärksten dieser Vorstöße gelangten öfter als jetzt bis in die inneren Tropen, d. h. es trat noch eine häufige Auflockerung und Durchbrechung der Urpassatdrift durch tropische Zyklonen ein.

Vor allem aber war der N-Saum der Sahara während aller pleistozänen Kaltzeiten auf Grund der offenbar immer wieder in ähnlicher Form sich abspielenden PolarfrontAnnäherung spürbar feuchter als heute. Wir nennen diesen Typ daher - in Übereinstimmung mit FLOHN - die "P ola re n Pluviale “ der Sahara. Er dürfte im wesentlichen durch Winterregen gekennzeichnet gewesen sein, wie das heutige Mittelmeergebiet. Diese Winterregen durchbrechen den gesamten Wüstengürtel heute regelmäßig nur noch längs des Roten Meeres (bis Massaua) und ostwärts längs des Persischen Golfes bis zu den „Weihnachtsregen“ an der Indusmündung. In der fast „spiegelbildlich“ in ähnlicher Breite wie die Sahara gelegenen inneraustralischen Wüste sind diese Durchbrüche subtropischer Winterregen bis in die Tropenregion heute viel häufiger, ähnlich wie es wohl während der Pluvialzeiten in der Sahara der Fall war.

Dies betrifft bereits die Verhältnisse am Sahara-S-Saum. Hier war der Einfluß der Kaltzeitenklimate doch viel lockerer und nur indirekt wirksam. Im Zuge der Feuchtzeitenfolge der letzten 10 Jahrmillionen ist er nur in zwei unterschiedlichen Wirkungen spürbar (Abb. 1). Einmal bedeutet die pleistozäne Klimawelle als ganzes hier ein großes Trockenintervall zwischen Pliozän und Holozän. Erst im Jungpleistozän kam es hier zu der einzigen Feuchtzeit, die wenigstens teilweise mit einer ektropischen E in z e 1 kaltzeit: der Würmzeit synchronisiert werden konnte. Während der Würmzeit (und vielleicht zurückgreifend bis in die Eem- oder gar in die Rißzeit) war tatsächlich die Sahara von allen Seiten: von N, von S und dazu von oben, von ihren reicher beregneten Gebirgsinseln her durch vorrückende Feuchtgürtel eingeengt.

Zur Entstehung dieses jungpleistozänen Südsaum-Pluvials haben sicher bis in die Tropen reichende Kaltluftvorstöße beigetragen. Aber es bleibt die Frage, warum dann 
die älteren Kaltzeiten, die doch von ähnlich großen ektropischen Kreislauf-Anomalien begleitet waren, hier keine entsprechenden Rückwirkungen erzeugten. Es muß hier also noch ein a nderer Einfluß dazugekommen sein. Dieser kann nur aus der Äquatorialregion selbst stammen. Alle atmosphärische Energie kommt von der Sonnenstrahlung, und die wirkte sich im äquatorialen Hitze- und Kreislaufgürtel der Erde stets am stärksten aus. Wir haben hier die wichtigste Umsetzungszone dieser Energie in unserer Lufthülle vor uns und damit einen Gürtel, der in seinen säkularen Schwankungen sicher auchi eigenen Gesetzen folgte. Sie interferieren mit Einflüssen, die in Zeiten besonders starker Abkühlung von den Polarkalotten ausgehen. Während des Pleistozän war dies aber hier auffälligerweise nur in der Würmzeit deutlich der Fall. Erst recht wurden vor und nach dem Pleistozän die Schwankungen dieses zentralen Luftgürtels von eigengesetzlichen, in ihm selbst wurzelnden Vorgängen bestimmt. In diesem Sinn nennen wir auch die jungpleistozäne Südsaum-Feuchtzeit ein äquatoriales Pluvial.

Noch mehr verdient die jungholozäne Feuchtzeit diese Bezeichnung. Hier fehlt die Beziehung zum ektropischen Kaltzeit-Warmzeit-Wandel ganz. Der kräftige Einsatz der neolithisch-postneolithischen Feuchtperiode am Sahara-S-Saum fällt nicht mit dem Beginn einer ektropischen Kaltzeit (Erniedrigung der mittleren Jahrestemperatur um $\mathrm{rd}^{\circ} 8^{\circ}$ ), sondern im Gegenteil mit dem Höhepunkt der holozänen Warmzeit (mittlere Jahrestemperatur in Mitteleuropa $\approx 2^{\circ}$ über heute) und dem beginnenden Absinken zur etwas kühleren Nachwärmezeit (die aber erst nach 1000 v. Chr. beginnt) zusammen. Steuernde Vorgänge aus dem ektropischen Zirkulationsbereich können somit daran nur geringen Anteil haben. Hierzu kommt, daß anscheinend der Einsatz dieser Feuchtzeit im Neolithikum besonders wirkungsvoll war. Denn auch für die zentrale Sahara bezeugen neolithische Felsbilder (mit reicher Jagdtierwelt sudanischen Typs, die mindestens Wüstensavanne mit Galeriewäldern voraussetzt) ein feuchteres Klima als heute. Es war nach Butzer (1958) als „Subpluvial II“ (rd. 5000-2500 v. Chr.) sogar bis Ägypten wirksam4). FLoHN (1963) wies auf die Existenz ähnlicher solcher Vorstöße bis in die jüngste historische Zeit hin. Vor allem aber darf man wohl aus dem kräftigen Einsatz dieser Feuchtzeit im Neolithikum, d. h. mitten in der langen, recht gleichmäßig temperierten postglazialen Wärmezeit der Ektropen (7000-500 v. Chr.) schließen, daß ihr Aktionszentrum nicht im Polarfront-, sondern im Äquatorialgürtel lag.

\section{c) Geologischer und klimatischer Aktualismus Der ausgeglichene Klimazustand der "Alten Tropenerde“}

Der geologische Aktualismus ist sicher real, soweit er sich auf endogene Vorgänge bezieht. Erdbeben, Verwerfungen, Flexuren, Faltungsparoxysmen, die Diagenese und Metamorphose der Gesteine sowie plutonische Ereignisse aller Art spielten sich vermutlich stets in „ähnlicher" Weise wie „heute“ ab, seit die feste Erdkruste besteht. In unzähligen Spuren sind uns darin die Folgen dieser Vorgänge bis in Vergangenheiten von Jahrmilliarden zurück weithin bekannt und gestatten die Verifizierung dieser These in vielen Einzelheiten.

Richten wir aber den Blick auf die exogenen Vorgänge, so liegen die Dinge völlig anders. Sie gehen ja letzten Endes alle auf Vorgänge in der Atmosphäre zurück. Dabei ist eine strenge begriffliche Scheidung nötig. In Bezug auf die sich hier abspielenden

4) FAIRBRIDGE (1962, S. 3) legt dagegen eine entsprechende Feuchtphase für Agypten in die Zeit von $9500-5000$ v. Chr., d.h. ins Mesolithikum vor das Neolithikum. Fast den gleichen Zeitraum - 8000-5000 v. Chr. - hält Burzer (1958, S. 145) in Agypten für "trockener als heute“ bzw. „dem heutigen Klima ganz ähnlich" (also auch sehr trocken). Beide Forscher stützen sich dabei auf "exakte“ Radiokarbondatierungen! Vielleicht liegt die Diskrepanz darin, daß von BUTZER lokale Wüstensedimente, von FAyrbRIDGE herkunftsmäßig ortsfremde Nil-HochflutSedimente untersucht wurden. Wir folgen oben deshalb zunächst BuTZER. 
meteorologischen Vorgänge ist das Gesetz des Aktualismus sicher gleichfalls weithin gültig. Ektropische Zyklonen und tropische Wirbelstïrme, Luftdruck und Windwechsel, die Entstehung von Strahlströmen und jeder Art von Niederschlag erfolgte sicher immer in ähnlicher Weise, seit auf der Erde eine Atmosphäre Festland und Meer bedeckt. Aber jeder dieser Vorgänge ist nur in dem verschwindend kurzen Augenblick seines gegenwärtigen Vollzuges zu erfassen. Von früheren Einzelvorgängen bleibt $\mathrm{n}$ i cht die ge ring $s$ t e S p u r zurück, weshalb der Geophysiker ja auch gar kein Interesse an dem - historisch belanglosen - Einzelprozeß, sondern nur an dem $\mathrm{T}$ y p u s eines Taifuns, einer Föhnlage, eines Frontgewitters hat. So ist ein meteorologischer Aktualismus zwar existent, aber mangels erhaltener direkter Spuren früherer Vorgänge vergleichsweise wesenlos. $\mathrm{Da}$ gegen sind ind i r k t e summierende Spuren der einstigen Verteilung solcher Vorgangstypen auf der Erde wenn auch nicht gerade reichlich erhalten, so doch von größtem historischen Interesse: eben die Spuren der vorzeit lichen Lage der Kli mazone n, um die es sich bei unserer Frage handelt. Auf diese für uns wichtigen Spuren ist aber das Gesetz des Aktualismus (etwa eines „klimatischen Aktualismus“) im Sinn des oben gekennzeichneten geologisch-endogenen kaum anwendbar. Ein Beispiel erläutert das am besten. In Schweden kann man selbst präkambrische Orogenesen in vielen Zügen noch genau verfolgen, ganz zu schweigen etwa von unserer alpinen, die man vom ersten Ansatz in der Unterkreide über ihre verschiedenen Hauptphasen bis zur letzten Mitfaltung der voralpinen Molasse Zug um Zug entschleiern konnte. Ähnliches fehlt in Bezug auf fossile Klimaspuren vollkommen. Wir kennen hier nur e in en Typ von Zirkulationsmodell genau: nämlich den von heute im Sinne der engsten Gegenwart! Erst seit etwa 20 Jahren ist ja das aerologische Beobachtungsnetz so dicht, daß wir wirklich von einer Kenntnis des Bewegungszistandes unserer Atmosphäre und damit des Bildungsvorganges der heutigen Klimazonen sprechen können. Nicht e in Zirkulationsmodell eines fossilen Klimas steht uns hier in direkten Spuren zur Verifizierung eines Aktualitätsprinzips zur Verfügung. Dazu kommt noch ein weiteres. Die spärlichen indirekten Spuren älterer Klimate, jeder vorzeitlichen Anordnung der Klimazonen auf der Erde, zeigen aber mit Sicherheit nur eines: daß diese Anordnung niemals derjenigen der Gegenwart entsprach! Das gilt sowohl vom „solaren“ Klima im ganzen wie von den Klimafaktoren terrestrischer Herkunft (Pollage, Land-Meer-Verteilung, Höhe und Streichrichtung der Gebirge. Existenz von Inlandeisdecken u. a.). Gegenüber der Frage, ob dabei die Solarkonstante wirklich immer konstant war, ist für uns wichtiger, daß die Troposphäre in ihrer klimabestimmenden Unterschicht etwa auf dem Höhepunkt der Würmkaltzeit im ganzen 5-6 ${ }^{\circ}$ kälter, dagegen im Alttertiär (wie im Großteil des Mesozoikums) mindestens um den gleichen Betrag wärmer war als heute $\left.{ }^{5}\right)$. Die terrestren Einflüsse auf das Klima waren vollends in allen geologischen Zeiten stets ganz andere als in der Gegenwart. Es erscheint uns deshalb nicht angebracht, hier allein von der schmalen Bezugsbasis der Gegenwart aus a lle älteren Klimazustände der Erde $\mathrm{n}$ u r als Abwandlungen des heutigen Zirkulationszustandes deuten zu wollen. Dies macht schon für manche Züge der uns zeitlich so nahestehenden Würmkaltzeit Schwierigkeiten. Etwa vom Klima der kontinentalen Löß-Tundra des Würm-Hochglazials mit ihrem hohen sommerlichen Sonnenstand und der üppigen Jagdtierwelt, die dem Aurignacjäger reiche Nahrung bot, können wir uns trotz vieler Spuren keine genaue Vorstellung mehr machen, weil es heute eben auf der Erde fast nur noch ewig nebelverhangene, hochpolar-ozeanische Tundrenklimate mit niedrigem Sonnenstand gibt. Aber wir können mit einigem Recht von der Gegenwart noch auf die Eem- und Holstein-Warmzeit, vom Würm auf die europäische Riß- und Mindelzeit zurückschließen, da hier die damaligen Vergletscherungen etwa der des Würm entsprachen. Aber schon für die Günzzeit war die Vergletscherung der Alpen und besonders Nordeuropas viel kleiner - ja im letzteren Fall fehlen überhaupt noch Spuren davon - obwohl andere

5) Vgl. auch GELLERT (1958) mit einschlägigen weiteren Literaturangaben. 
Anzeichen eine ähnliche Abkühlungsgröße für das Günz wie für das Würm vermuten lassen. Kurz: je weiter wir in die Vergangenheit zurückgehen, desto unsicherer und gezwungener wird der Versuch, fossilen Klimazuständen das Schema des heutigen Zirkulationssystems zugrunde zu legen, jene noch als eine Abwandlung von diesem verstehen $\mathrm{zu}$ wollen.

Unter solchen Umständen scheint es nützlich, einen anderen methodischen Weg zu versuchen. Er geht davon aus, daß mindestens die Evolution der terrestrischen Einflußfaktoren auf das Klima umgekehrt, d. h. von der Vergangenheit auf die Gegenwart zuschritt. Zweitens von der Erkenntnis, daß die letzte Jahrmillion des Quartär mit ihren raschen schlagartigen Klimaumbrüchen eine klare Ausnahmesituation, ein „Paroxysmus“ der irdischen Klimaentwicklung war, die vorher seit dem jungpaläozoischen Eiszeitalter über 200 Jahrmillionen lang in sehr viel gleichmäßigeren Bahnen verlief. Es gilt nun, innerhalb dieser Beharrungsperiode einen Ausgangspunkt zu wählen und von diesem aus über die wechselnden, aber mit der Annäherung an das Holozän immer deutlicher konstruierbaren terrestrischen Klimaeinflüsse allmählich bis zu dem gesicherten Fixpunkt des Gegenwartsklimas fortzuschreiten, das man bei diesem Weg ja ständig im Auge hat, ohne durch dies für so alte Zeiten sicher stark irreale Denkmodell gleich zu Beginn gefesselt zu sein.

Dieser Ausgangspunkt muß eine lange kontinuierliche Klimaphase sein, die noch deutlich vor der quartären Störungsperiode, aber doch nahe genug an der Gegenwart liegt, um genügend Spuren für eine nicht allzu hypothetische erste Rekonstruktion zu bieten. Als solche empfahl sich der lange Zeitraum vom Eozän bis zum Unterpliozän. Durch diese rd. 50 Jahrmillionen bewahrte die ganze Erde bis in hohe Breiten ein gleichmäßig warmes Klima. Wir kommen so zu dem Begriff der „A l t e n T r o p e n e r d e “ (Büdel, 1962). Ferner suchten wir schon oben (S. 166) zu zeigen, daß das damalige Temperaturniveau auch weiterhin (bei einigen hygrischen Schwankungen) nur so langsam abnahm, daß bis zum Oberpliozän im südlichen Mitteleuropa (46,5-50 $\mathrm{NBr}$.) noch kein grundsätzlicher Wandel der Bodenbildung und der Abtragungsbedingungen eingetreten war.

Die „Alte Tropenerde“ barg keine Art von Kaltklimaten, geschweige denn vereiste Polarhauben. Die Polargebiete hatten etwa das Klima der heutigen "gemäßigten Zone“ (Schwarzbach, 1961, Klima-Karte des Alttertiär, S. 158). Warmklimate etwa vom Typ der heutigen Tropen und Monsunal-Subtropen reichten bis in die höheren Mittelbreiten. Damit war der äquatoriale Wärmegürtel der Erde (heute rd. 48\% der Erdoberfläche) auf über 70\% ausgeweitet. Eine Reihe von Gründen spricht dafür, daß er dennoch - auch in seinem Kern - nicht wärmer war als heute. Viele geologisch-paläontologische Reste zeigen ferner, daß die räumliche Temperaturabnahme zum Pol hin sich ganz allmählich ohne Sprünge vollzog. Mit dem verringerten Temperaturgegensatz zwischen Pol und Äquator waren die zonalen Druckgegensätze vermindert und damit der Hauptmotor der zonalen Klimagliederung geschwächt. Weitere Umstände verstärken diese Wirkung: das Zurücktreten von Hochgebirgen (dic Hebung der Alpen und vieler anderer alpinotyp gebauter Gebirge setzt erst im Pliozän voll ein) und die gleichmäßig hohe Temperatur eines (beim Fehlen von Inlandeisgebieten) hochgespannten, viele Schelfe überflutenden Weltmeeres; selbst kontinentale Binnenbecken waren noch im Mittelpliozän von Flachmeeren oder großen Binnenseen bedeckt.

Das alles bedeutet die Herrschaft eines anderen und zwar vor allem eines deutlich abgeschwächten Zirkulationssystems. Wenn eine der heutigen Polarfront ähnliche Grenzfläche in der damaligen Atmosphäre überhaupt schon existierte, so lag sie nahe am Pol auf kurzen Breitenkreisen und entbehrte des Rückhaltes einer großen Kaltlufthaube. Auch Westwindgürtel müssen, wenn sie existierten, in ähnlicher Polnähe gelegen haben (FLOHN, 1963). Spuren davon kennen wir nicht. Vor allem aber fehlen solche von ausgeprägten subtropischen Hochdruckgürteln aus jener Zeit. Die oben angeführten Beispiele aus dem Burdigal, dem Torton und dem Pont Mitteleuropas deuten 
darauf hin, daß gleichmäßige - vermutlich schwache - passatartige Ostwinde die Erde vom Aquator bis weit in die Mittelbreiten hinein beherrschten, was auch zum thermischen Bild der polwärts weit ausgedehnten "Alten Tropenerde“ paßt. Tropische Wüstengebiete gab es wohl, aber sie waren weniger an zonal-stabile Hochdruckgürtel als an die Binnenräume und leeseitigen Küsten der Kontinente geknüpft. Darüber hinaus können überall im Bereich dieser großen allgemeinen Ostströmung lokale Trocken- und selbst Wüstengebiete an den Leeseiten und ebenso ausgeprägte Regengebiete an den Luvseiten jedes Gebirges bestanden haben, so wie heute noch in dem gleichförmigen Passatklima des Pazifik selbst kleine Inseln eine stets regenfeuchte Luv- und eine wüstenhaft-trockene Leeseite haben können, soweit auch heute noch dort Polarlufteinbrüche mit der Anregung zyklonaler Tätigkeit und der Bildung von Aufgleitfronten im Luftmeer selten sind und auch das äquatoriale („Monsun“-) Westwindband solche Inseln selten erreicht. Die ganze Erde war ja damals noch viel „ozeanischer" als heute.

War solcherart die Zon algliederung der „Alten Tropenerde“ wenig ausgeprägt, so fehlten damals erst recht die Motoren $\mathrm{zu}$ meridion al weit vorstoßenden Druckwellen.

Wie die räumliche so war auch die zeit 1 iche Differenzierung: der Wechsel von Regen- und Trockenzeiten, welche den Großteil der heutigen Tropen so auffällig beherrscht, damals (wenigstens gebiets- und zeitweise) weniger ausgeprägt. Gezielte Untersuchungen in dieser Richtung unternahm RuTte (1956, 1961, 1963) mit seinen Schülern im Sarmat und Pont der oberdeutschen Süßwassermolasse. Ahornarten, deren nächste Verwandte heute stets einen (thermisch oder hygrisch) rhythmischen Blätterfall zeigen, warfen damals ihre Blätter gleichmäßig durch das ganze Jahr hindurch ab. Ostracoden (Muschelkrebse), deren Jugendstadien heute stets jahresrhythmisch auftreten und die daher auch als besonders gute fossile Jahreszeit-Indikatoren gelten, ließen damals auch in „Rythmiten, die gerne als jahreszeitlich geschichtet angesehen werden" keinerlei entsprechende Sortierung erkennen. Das gleiche zeigt dort der Anfall von Cypriniden-Schlundzähnen, die heute ebenfalls eine besonders deutliche Jahreszeiten-Rhythmik zeigen, wobei übrigens unter neun untersuchten Arten acht als vollkommen identisch mit den rezenten erkannt wurden. Auch sonst stimmen viele von Rutre ermittelte Züge der Umwelt jener Biotope mit dem geschilderten Bild überein: weite Spülfluten rasch wechselnder Flußarme sowie das ganze Jahr hindurch ziemlich einheitliche und dabei relativ höhere Wassertemperaturen. Bemerkenswert ist, daß diese Beobachtungen bereits aus der Ausklangszeit der "Alten Tropenerde“ stammen. Mit Recht betont Rutre, daß es für die damaligen Klimazustände Süddeutschlands heute auf der ganzen Erde kein Analogon gibt, weder in den Tropen noch in den Subtropen.

Im ganzen war die so sehr verbreitete warme Zone der „Alten Tropenerde“ gegenüber der heutigen schmäleren, aber viel reicher differenzierten Tropen- und Subtropenzone von einer ermüdenden räumlichen und zeitlichen Gleichförmigkeit in allen Wetterelementen. Viele Lebensformen blieben daher damals durch lange geologische Perioden unverändert $\left.{ }^{6}\right)$. Am ehesten finden wir heute auf hochozeanischen Inseln vom Äquator bis in hohe Breiten ähnlich ausdruckslose Klimaübergänge.

6) Die "Alte Tropenerde" als eine Zeit relativ gleichmäßiger Faunenentwicklung (insbes. der Säugetiere) liegt nach SCHINDEwOLF (1960) zwischen zwei entscheidenden Umbrüchen auf diesem Gebiet: einem im Eozän und einem an der Plio-Pleistozänwende. Beide aber waren höchst ungleichwertig. Einleitend im Eozän treten allein unter den Unpaarhufern (Pferde- und Tapirstämmen) in kurzer Zeit 12 neue Ordnungen mit bisher völlig unbekannten Bauplänen auf. Acht davon sterben zwar alsbald (noch mit dem Eozän) wieder aus, aber 4 hielten sich mit geringen Abwandlungen bis zur Schwelle des Quartärs. Erst dann setzen viele neue Formen plötzlich ein, aber nur vom Rang von Gattungen und Arten, also nur Anpassungs-Abwandlungen, nicht die Neubildung von Ordnungen mit völlig anderen Bauplänen. Bemerkenswert ist, daß Schindewolf diese Ergebnisse auf Grund gleichartiger Beobachtungen a uf der ganzen Erde gewann. 


\section{a) Die Zonal-Differenzierung des Zirkulationssystems}

$$
\text { im Pliozän }
$$

Wie Abb. 1 zeigt, war das Pliozän am Sahara-N-Saum trocken, am S-Saum durchwegs feucht. Die (doppelte) Klimawende des Villafranca bringt hier wie dort eine Wandlung. Im Norden beginnt die Serie der im wesentlichen kaltzeitgebundenen pola re n Pluviale. Im $S$ beginnt eine längere Trockenzeit, die erst im Jungpleistozän wieder von einer deutlichen Feuchtzeit äquatorialen Charakters abgelöst wird. Von ihrem Typus weicht die Genese der Südsahara-Feuchtzeit des Pliozän noch etwas ab.

Im Lauf des Pliozän wich der N-Saum des von der „Alten Tropenerde“ überkommenen Warmklimagürtels auf der N-Halbkugel von rd. $60^{\circ}$ auf etwa $45-50^{\circ}$ zurück. Ähnliches geschah vermutlich auf der Südhalbkugel. Diese Verschmälerung des irdischen Wärmegürtels wurde anscheinend von einem inneren Strukturwandel, einer Differenzierung in schärfer geprägte Zonen begleitet. Man kann sich das etwa wie folgt vorstellen. Im gleichen Maß, wie der Rand der Tropenzone zurückwich, läßt sich die stetig weiterschreitende Abkühlung der Polarkalotten verfolgen. Gleichzeitig dehnten sich ihre Areale aus, rückten die an ihren Rändern sich verstärkenden „Polarfronten“ $\mathrm{n}$ ä h e r an den Äquator heran. Beide Umstände verstärkten das planetarische Temperaturgefälle und damit die zonalen Druckunterschiede. Im Unterpliozän bildete sich zunächst am Sahara$\mathrm{N}$-Saum ein Trockengürtel. Vielleicht kann man in ihm den Beginn eines durchlaufenden subtropischen Hochdruckgiirtels erblicken, der sich im Laufe des Mittel- und Oberpliozän südwärts ausdehnte und zur Zeit der Plio-Pleistozänwende etwa schon die heutige Breitenlage zwischen $18^{\circ}$ und $33^{\circ} \mathrm{NBr}$. erreicht hatte. Aber polwärts von ihm schloß sich im obersten Asti und frühen Villafranca noch nicht - wie heute - ein von winterlichen Polarluftvorstößen beherrschtes Mittelmeerklima und dann unser gemäßigtes SommerregenWestwindklima an. Vielmehr war auch das Klima Mitteleuropas im Villafranca noch subtropisch-warm, wobei wohl trockenere Steppen- und feuchtere Waldklimate aufeinanderfolgten, aber noch wenig von Polarlufteinbrüchen und kalten Wintern zu spüren war $\left.^{7}\right)$. Mechanische Verwitterung, stärkere Schotterführung und Talbildung der Flüsse zeigten erst schwache Ansätze (s.o.).

Im ganzen scheint es, daß sich solcherart im älteren Villafranca in erster Linie noch die stärkere zonale Klimagliederung fortsetzt, die sich schon im Pliozän angebahnt hatte. Mit dem entstehenden subtropischen Hochdruckgürtel war dabei, von $\mathrm{N}$ her beginnend, die Sahara als geschlossene Wüste entstanden ${ }^{8}$ ). Möglicherweise gewann erst gleichzeitig damit der verschmälerte Feuchtgürtel der inneren Tropen mit dem strengeren Jahreszeitwechsel von Ost- und Westwinden, von Regen- und Trockenzeiten die typischen Charakterzüge der heutigen Tropenzone.

e) Das Aufkommen meridionaler Zirkulationsgrupen und

die Asymmetrie der Sahara-Pluvialfolge im Pleistozän

Zwischen den beiden Klimastürzen: dem ersten an der Wende Asti-Villafranca und dem zweiten an der Schwelle der ersten ältest-pleistozänen Kaltzeit (etwa: letzter Abschnitt des Villafranca) mag eine Zeitspanne von 2-3 Jahrhunderttausenden liegen. Es ist dabei wichtig, festzuhalten, daß etwa in Mitteleuropa nicht schon am Anfang, sondern

7) Die Existenz ausgeprägter Trockenklimate im Villafrancha Mitteleuropas (bei weiterer Meeresverbreitung als heute!) ist mit der Herrschaft von Westwinden ebenso schwer vereinbar wie die der älteren Trockenzeiten aus dem Helvet (RutTe, 1963) und Sarmat (WINKLER, 1957).

8) Dies schließt nicht aus, daß. Teilräume der Sahara auch schon früher gelegentlich „warmes Trockenklima“, wenn auch nicht gerade so extremes Wüstenklima wie heute zeigten (ScHWARzВАСC, 1953). Auf großen, geschlossenen Festländern mit tropischem Ostwindklima konnte das zeit- und strichweise Auftreten von Binnen- und Leeseiten-Trockenklima (s.o.) z. B. schon eine Folge der im Tertiär ja vielfach wechselnden Meerestransgressionen sein. Se'bst in Mitteleuropa traten ja zur Zeit der "Alten Tropenerde“ gelegentlich Trockenphasen auf (s. Anm. 7). 
erst am Ende dieses Abschnittes (jüngeres Villafranca) das ungefähre Temperaturniveau der späteren Interglazialzeiten und des Holozän erreicht bzw. nach unten durchschritten wird. Aber nur die sola re n Klimabedingungen von damals waren den heutigen schon ähnlich. Die terrestris chen Faktoren waren noch völlig andere. Auch der Klimasturz zur ersten Kaltzeit selbst vollzog sich noch unter anderen Bedingungen. Aus den Prägünz-Kaltzeiten kennen wir noch keine sicheren Vergletscherungsspuren, und auch die Günzzeit stand hierin vielerorts gegen die späteren Eiszeiten zurück. Das Vorhandensein großer Vereisungen ist aber ein wesentlicher selbstverstärkender Faktor klimatischer Eiszeitwirkungen.

Solcherart an Stärke zunehmend erfolgte in den Kaltzeiten ein neuerlicher Umbau der atmosphärischen Zirkulation. Die nordhemisphärische Polarfront, im Villafranca noch jenseits von $60^{\circ} \mathrm{NBr}$., heute bei etwa $45-50^{\circ} \mathrm{NBr}$. gelegen, rückte bis fast $30^{\circ} \mathrm{NBr}$. vor und erreichte damit auch an (begradigter) Längenausdehnung fast schon den Umfang eines Großkreises. Dementsprechend vergrößerte sich das jetzt erst tief abgekühlte Kaltluftreservoir der Polarkalotten: auch die untere Tropospäre der Erde bestand jetzt im Nordwinter zu annähernd $30 \%$ aus Luftmassen um bis tief unter den Gefrierpunkt. Ähnliches war seit mindestens 200 Jahrmillionen, vielleicht aber überhaupt noch nie auf der Erde der Fall gewesen.

Die Wirkung auf die Zirkulation dürfte dreifach gewesen sein. Durch das weitere Vordringen beider Polarfronten wurden einmal die Warmklima z o n e n weiter in Äquatornähe zusammengedrängt, Temperatur- und Druckgegensätze und damit auch die mittleren Windgeschwindigkeiten verstärkt: die subtropischen Hochdruckgürtel und die äquatoriale Tiefdruckrinne somit trotz ihrer Verschmälerung im ganzen wohl noch ausgeprägter. Aber dieser Effekt wurde durch einen zweiten überlagert. Aus dem stark vergrößerten Kaltluftreservoir, besonders der landreichen Nordhalbkugel, stießen bei verstärktem Druckgefälle auch häufigere und kräftigere Kaltluftzungen weit äquatorwärts vor. Die Polarfront bot so ständig ein stark gebuchtes Bild. Ihre Ausläufer zerteilten den subtropischen Hochdruckgürtel häufig - besonders im N-Winter - in einzelne Zellen. Häufiger als heute gelangten solche Kaltluftvorstöße als zyklonale Regenbringer selbst in die inneren Tropen. Mit der weiteren Verstärkung der zonalen Druckgegensätze ging also eine Auflösung der Warmklimazonen durch die von $F_{L O H N}(1952,1963)$ und anderen dargestellter Verstärkung der Meridionalzirkulation während der Kaltzeiten parallel.

Wir kommen abschließend zur Frage der auffälligen Asymmetrie der saharischen Pluvialzeitfolge am $\mathrm{N}$ - und am S-Saum. Erst spät, im Jungpleistozän kommt es zu dem Bilde, das die Grundlage der über die ganze Erde gespannten Klimarekonstruktion der Würmzeit durch FLOHN und andere bot. Es müssen sich also bestimmte Züge des aus der Würmzeit vertrauten Bildes des „Eiszeitklimas“ erst a $11 \mathrm{~m}$ ählich während des Pleistozän entwickelt und schließlich kumuliert haben. Welche Faktoren waren dies? Sicher vor allem terrestrische. Es kommt, so weit wir sehen, eine Vierheit solcher Faktoren mit engen wechselseitigen Beziehungen in Betracht.

\section{1) Fortschreitende Gebirgshebungen im Quartär}

Ozeanflächen fördern zonale, dagegen Festland, besonders nordsüdlich ziehende Hochgebirge meridionale Zirkulationstypen. Diese Unterschiede konnten aber wohl erst d a n n voll wirksam werden, seit die Entwicklung der planetarischen Zirkulation bis zum Auftreten meridionaler Zirkulationstypen vorgeschritten war, d. h. mit dem Einsatz der quartären Kaltzeiten. Ein solcher Typus konnte sich von vornherein auf der landreicheren Nordhalbkugel besser entfalten. Diese Wirkung steigerte sich im Lauf des Quartär. Es spricht vieles dafür, daß im Altestpleistozän, ja z. T. noch im Günzglazial, 
manche Gebirge erst weniger emporgehoben, also noch niedriger waren als heute. Doch war dieser - vielfach vermutete, aber im einzelnen schwer nachweisbare - Faktor sicher der unwichtigste der genannten Vierheit.

\section{2) Der Gang der Inlandeisbildung auf der Nordhalbkugel}

$\mathrm{Ob}$ es an der noch mangelnden Hebung vieler Gebirge oder an klimatischen Ursachen (z. B. einer noch geringeren Depression der Schneegrenze) lag: jedenfalls waren die Prägünz-Kaltzeiten auf der Nordhalbkugel noch nicht von größeren Inlandeisbildungen begleitet. In der Günzzeit aber bestand mit demjenigen Nordamerikas schon ein Großteil der nordhemisphärischen Inlandeisschilde späterer Kaltzeiten ${ }^{9}$ ). Besonders ein früher Aufbau des weit in den warmen Nordatlantik hineinragenden hohen grönländischen Eisschildes muß - wie heute - südwärtige Polarluftvorstöße an der Westseite der alten Welt stark gefördert haben. Als dann - spätestens in der Mindel-(Elster-) -Zeit — erstmals der Kaltzeit-Aufbau des nordeuropäischen Inlandeises vollendet war, d. h. ein von FranzJosef-Land bis Südirland $4000 \mathrm{~km}$ langes, bis $1700 \mathrm{~km}$ breites und $3000 \mathrm{~m}$ hohes Plateaugebirge aus Eis, das keine Tieflandslücken kannte, sich vom Polargebiet bis zum 52. Breitengrad herab vor die Westküste Europas legte, wurden hier Westwinddrift und subtropische Hochdruckgürtel während der Kaltzeiten in einem sonst auf der ganzen Erde kaum wieder erreichten Maß durch meridionale Kaltluftvorstöße aufgelöst.

3) Die schrittweise Absenkung der interglazial-eustatischen Ozeanstände

Diese bei annähernd gleichgroßer Abkühlung doch von einer Kaltzeit zur anderen zu nehmende Meridionalzirkulation auf der Nordhalbkugel wird noch durch einen dritten Umstand gefördert. Es ist die im Laufe des Quartär schrittweise fortschreitende eustatische Absenkung des Ozeanspiegels, die in dem allmählich immer größeren Anwachsen der kaltzeitlichen Inlandeisschilde begründet liegt. Schelfmeere, die in der Würmzeit trocken lagen oder sogar (Barentsseeschelf!) hohe Inlandeisschilde trugen, waren während der ersten Kaltzeiten noch Meeresflächen und begünstigten die Zonalzirkulation. Außerdem war bei geringerer Ausdehnung der kalten Polarkalotten das hochgespannte Weltmeer des älteren Pleistozän auch als ganzes wärmer, sowohl in Bezug auf das kalte ozeanische Tiefenwasser als auch auf oberflächliche kalte Strömungen, die ja heute etwa in Gestalt der Fortsetzung des Humboldt- und Benguela-Stromes noch in die Südäquatorialströmung des Pazifischen und Atlantischen Ozeans eingehen ${ }^{10}$ ).

Indessen sind dies alles schon Folgen des allmählichen Aufbaus der antarktischen Polarluftkalotte. Ihr folgte der Aufbau des Inlandeises nach (wobei es den Aufbau jener Kaltlufthaube selbstverstärkend konsolidierte). Von der Peripherie der Kaltlufthaube stammt die überwältigende Menge des kalten Tiefenwassers aller drei Ozeane. Ein Schmel-

9) Bei der doppelten Nachbarschaft des stark abgekühlten innerpolaren Gebietes (Nordamerika Polarmeer - Sibirien) un d des für reiche (Schnee-) Niederschlagszufuhr in diesem Gebiet sorgenden Golfstrombereiches ist die Annahme nicht unberechtigt, daß die erste Vergletscherung Grönlands v o r der des übrigen nordamerikanischen Kontinents einsetzte. Zweifelhafter ist dies für den Bereich des Barentseeschelfes. Dieser war nach den Ergebnissen der "Stauferland“-Expedition im Tertiär weithin Festland und wurde erst im (Präglazial und) Quartär infolge tektonischer Senkungen überflutet (WirthmanN, 1962). W a n n dann diese Absenkung mit der im Laufe des Quartär sich vollziehenden eustatischen Ozeansenkung so weit zusammenklang, daß dort im Frühglazial einer Kaltzeit ein hinreichend breiter Sockel Pandfest wurde, der zur Anlage eines Inlandeises dienen konnte, ist noch ungewiß. Sicher konnte dagegen festgestellt werden, daß der Barentseeschelf in der Würmkaltzeit auf seiner nördlichen (Spitzbergen-Franz-Josef-Land) und östlichen (Nowaja-Semlja) Randschwelle ein Inlandeis im Umfang von rd. $800000 \mathrm{~km}^{2}$ trug (BüDEL, 1962). Nimmt man seine mittlere Mächtigkeit zu $500 \mathrm{~m}$ an, so ergibt das $400000 \mathrm{~km}^{3}$ Eis und $360000 \mathrm{~km}^{3}$ Wasser. Dies entspricht einem Ozeananstieg von $1 \mathrm{~m}$.

10) Nach FlOHN (1963) wurde ein im ganzen nur um $5^{\circ}$ wärmerer Ozean allein infolge der Dichteänderung des Meerwassers um 2,66 m ansteigen. Im ganzen Ozean die Tiefentemperaturen des Mittelmeeres vorausgesetzt, würde allein dadurch ein Ozeananstieg von rd. $5 \mathrm{~m}$ erzeugt werden. 
zen des Inlandeises hingegen ließe den Ozeanspiegel heute um $66 \mathrm{~m}$ ansteigen (Hornkes, 1961, Flohn, 1963), wobei die Ausdehnung der Meeresfläche durch Überflutungen von Tiefländern schon mitgerechnet ist. Zusammen mit der höheren Temperatur des Ozeans in der Zeit würde dies einen gegenüber heute um $\mathrm{rd}$. $70 \mathrm{~m}$ höher gespannten Ozean vor dem Aufbau des antarktischen Inlandeises bedeuten. Setzen wir voraus, daß im Altestpleistozän vor dem Anbruch der ersten Kaltzeit auch die übrigen auf der Erde heute vorhandenen Gletscher und Inlandeise (vor allem Grönland) noch nicht existierten, so entspräche das einem weiteren Ozeananstieg von 7-8 $\mathrm{m}$. Bei Berücksichtigung einiger Nebenumstände läuft das alles auf ein gegenüber heute ziemlich genau um $75 \mathrm{~m}$ höheren Ozeanstand für die Zeit vor dem Aufbau der irdischen Vereisungsgebiete hinaus. Die Frage ist nun: wann wurde die Hauptursache des seitherigen eustatischen Ozeanrückzuges: das antarktische Inlandeis aufgebaut?

4) Der verzögerte Aufbau des antarktischen Inlandeises

Es ist merkwürdig, wie spät die - längst bekannte - Tatsache der schrittweisen eustatischen Absenkung des Weltmeeres im Verlauf des Pleistozän mit dem \pm gleichzeitigen Aufbau der Inlandeisgebiete, insbesondere des antarktischen verbunden wurde (vgl. BüDEL, 1960, S. 43). Die alten höheren Spiegelstände wurden vor allem an den Küsten des Mittelmeeres, des Roten Meeres und sonstiger Punkte Südasiens sowie an der Atlantikküste Westeuropas und Nordafrikas festgestellt, d. h. also mindestens teilweise in Räumen mit deutlichen Küstenhebungen in der jüngeren geologischen Vergangenheit. Wir schieden aus diesem Grunde auch die älteste kalabrische Stufe (=Villafranca) aus dieser Betrachtung aus. Sie liegt häufig rd. $180 \mathrm{~m}$ über dem Meer, ist aber vielfach in Gestalt einwandfrei tektonisch gehobener weiter Altflächen ausgeprägt, die im Hinterland der genanten Küsten ganze Landstriche überziehen. Zu einer auch nur annähernd sicheren Bestimmung des Ozeanstandes im (tieferen) Ältestpleistozän scheinen sie mir ungeeignet; auch SchwarzвАCH (1961) hat sie wohl deshalb den eigentlich pleistozän-eustatischen Meeresterrassen nicht mehr zugerechnet.

Wir beginnen deren Reihe mit den Terrassen des Sizil, die für eine Prägünz-Warmzeit einen rd. $100 \mathrm{~m}$ höheren Ozeanstand anzeigen. Durch die Terrassen des Milazz wurden für das Günz-Mindel-Interglazial rd. $60 \mathrm{~m}$ Ozeanstand über dem heutigen ermittelt, für das große Mindel-Riß-Interglazial (Tyrrhen I) $28-40 \mathrm{~m}$ und für das Riß-Würm-Interglazial (Monastir oder Tyrrhen II) gar nur $18-20 \mathrm{~m}$.

Natürlich fielen diese Hochstände immer in Warmzeiten. Diese stimmten untereinander und auch mit dem thermischen Niveau des Holozän durch das ganze Eiszeitalter weitgehend überein. Trotzdem zeigen die älteren einen immer höheren Stand des Weltmeeres an. Man hat zur Erklärung dieser Tatsache bisher meist tektonische Ursachen, z. B. eine teilweise Absenkung des Tiefseebodens im Verlauf des Pleistozän angenommen. Eine solche Annahme ist mechanisch schwer erklärbar, Beobachtungsgrundlagen gibt es dafür nicht. Hingegen sprechen mehrere erweisbare Umstände deutlich dagegen. Einmal: Die Absenkung des Ozeanspiegels im Lauf des Pleistozän ist eine Tatsache. Das bedeutet auf jeden Fall eine Entlas tung der Ozeanböden (wenn auch nur um 15-20\%/o0), jedenfalls aber keine isostatische Belastung $\left.{ }^{11}\right)$. Wären aber aus anderen - rein tektonischen - Grün-

11) Eine isostatische Belastung fand durch die Inlandeiskuchen auf deren festländischer Unterlage statt: diese wurde dadurch eingedrückt und gleichzeitig ein ringförmiges Randgebiet etwas angehoben. Manchmal war dies auch ein Meeresgebiet. Nun beträgt das spezifische Gewicht des Eises $33 \%$ der meisten Sialgesteine. Wegen deren Zähigkeit setzte sich aber nur ein Bruchteil davon als wirk'icher Eindrückungsbetrag auf die Unterlage um (im Mittel nach Erfahrungen aus Skandinavien und Nordamerika etwa 15\%). Noch geringer war aus demselben Grunde der gleichzeitige Hebungsbetrag des Randwulstes. Solche Wulste ergriffen ihrerseits nur z. T. Meeresböden. Alle diese isostatischen Bewegungen wurden außerdem in der nächstfolgenden Warmzeit durch Rückbewegungen weithin ausgeglichen. So bleibt im Endeffekt die errechenbare Wirkung dieser Eisisostasie auf den Ozeanspiegel eine gegenüber dessen eustatischer Absenkung zu vernachlässigende Größe. 
den während des Pleistozän größere Absenkungen in Ozeangebieten erfolgt, so hätten diese wahrscheinlich auch Küstenstriche mit ergriffen. Gerade aber davon läßt die weithin gleich hohe Lage der warmzeitlichen Meeresstrand-Spuren nichts erkennen.

Viel ungezwungener und wahrscheinlicher scheint mir daher die Annahme, für die stufenweise Absenkung der warmzeitlichen Spiegelstände den fortschreitenden Aufbau der großen Gletscher im Laufe des Pleistozän, vor allem den des antarktischen Inlandeises verantwortlich zu machen. Der aus diesem Aufbau für die Ozeansenkung e r r e c h n e t e Betrag von $75 \mathrm{~m}$ und der tatsächlich (auf Grund einer Unsumme übereinstimmender Einzelbeobachtungen) beobachtete Betrag von rd. $100 \mathrm{~m}$ seit dem Sizil und rd. $60 \mathrm{~m}$ seit dem Milazz stimmen größenordnungsmäßig in befriedigender Weise überein. Es muß daher als wahrscheinlich gelten, daß größere Vergletscherungen in den PrägünzWarmzeiten auf der Erde noch nicht existierten (bzw. von einer Prägünz-Kaltzeit nicht in eine so frühe Warmzeit hinein fortdauerten), vor allem nicht in der Antarktis. Das Günzglazial brachte die ersten größeren Vergletscherungen, nach den unmittelbaren Spuren (s. o.) vor allem in Nordamerika und Grönland. Der 60-m-Ozeanstand im folgenden Günz-Mindel-Interglazial (Milazz) wäre durch die Annahme einer Perexistenz des Grönlandeises (im heutigen Umfang) sehr weitgehend erklärt (75 m weniger 7-8 m, dazu einige Nebenumstände $\approx 65 \mathrm{~m}$ ); ein bede ut e $\mathrm{nde} r$ Inlandeisschild durfte also auch damals in der Antarktis noch nicht bestanden haben, höchstens der Ansatz dazu. Dagegen müßte man für den während des großen Mindel-Riß-Interglazials (Tyrrhen I) von 40 auf $28 \mathrm{~m}$ absinkenden Meeresspiegel schon mit einem - möglicherweise gerade in dieser Warmzeit rasch fortschreitenden - etwa halben Aufbau des antarktischen Eises rechnen, der sich dann im Verlauf des Eem-Interglazials (Tyrrhen II oder Monastir) bei bereits den heutigen angenäherten Spiegelständen vollendet hätte.

Die hiergegen möglichen Einwände haben m. E. kein diese Hypothese aufhebendes Gewicht ${ }^{12}$ ), ganz abgesehen davon, daß dann für die eustatisch-quartäre Meeressenkung zu sehr fernliegenden, unbewiesenen Hilfshypothesen gegriffen werden müßte. Im übrigen steht unsere Theorie des ( \pm parallel zur quartären Ozeansenkung) verzögerten Aufbaus des antarktischen Inlandeises zu keinem Ergebnis der modernen Antarktisforschung (vgl. Hornkes, 1961) im Widerspruch. Mehrere dort erzielte Ergebnisse vermögen sie vielmehr zu festigen. Das erste: der Felssockel des antarktischen Inlandeises liegt durchwegs viel tiefer als man bisher annahm, nämlich „in weiten Gebieten des antarktischen Kontinents nahe dem heutigen Meeresniveau, z. T. sogar erheblich tiefer" (maximal $2500 \mathrm{~m}$ unter dem Meeresspiegel, Hoinkes, 1961, S. 359-360). Geht man selbst von den

12) Die dicht vor dem Eisrand des Mc-Murdo-Sundes gelegenen „ältesten“ Moränen gleich bis ins Mindel zurückzuverlegen, ist eine rein schematische Parallelisierung nach anderen Vereisungsgebieten, die gerade für die Antarktis wenig überzeugen kann (HoINKES, 1961). Da außerdem der einzige einwandfrei nachgewiesene fossile Hochstand des antarktischen Inlandeises $(300-800 \mathrm{~m}$ $\mathrm{m} \ddot{\mathrm{c}} \mathrm{cht}$ ig e r als heute!) wahrscheinlich aus der Eem-Zeit stammt (s. u.), ist die Erhaltung älterer Moränen schwer vorstellbar.

Wenn die Bodenwassertemperaturen des Pazifischen Ozeans nach FurNT (1957) schon seit der Tertiärmitte (wenn die Altersbestimmungen der Tiefsee-Sedimente zutreffen!) langsam absinken, so liegt darin kein Beweis, daß sich „das Eis am antarktischen Kontinent lange vor dem Quartär, im Miozän (!) oder Pliozän zu bilden begonnen hat" ${ }^{\text {" }}$. Denn auch heute stammen die aus den Polarräumen absinkenden kalten ozeanischen Tiefenwässer nicht vom kalten Süßwasser der schmelzenden Gletscher und Eisberge her, das wegen seines geringen Salzgehaltes oben schwimmt, sondern von der frühwinterlichen Abkühlung der Meeresoberfläche a u ßerhalb der Packe is g renze (und erst recht außerhalb der Schelfeis- und Inlandeisränder!), wie dies Wüst (1928) für die Antarktis erwies. Für die Arktis spielt sich derselbe Vorgang - ebenfalls weit abseits aller eisbergliefernden Inlandeisgebiete - im Frühwinter auf den Schelfmeeren, besonders vor der Nordküste Asiens ab. - Ernster zu nehmen ist die Hypothese von FaIRBRIDGE (1961) über einen bereits im Prägünz beginnenden langsamen Aufbau des antarktischen Inlandeises, auf die FloHN (1963) zurückgriff. Die Begründung unserer in diesem Punkt abweichenden Hypothese folgt unten im Text. 
ungünstigsten Prämissen aus, d. h. korrigiert man den vollen Betrag der heutigen isostatischen Eindrückung der Felsunterlage (nach HorNKEs „einige Hektometer, nach dem oben genannten Erfahrungsatz also rd. 400-500 m) hinzu und vernachlässigt man ferner, daß z. B. das zentrale antarktische Horstgebirge erst durch tektonische Hebungen im Laufe des Quartär seine volle heutige Höhe (2000-3000, max. $4500 \mathrm{~m}$ ) erreicht haben könnte, so ergibt sich doch für die Zeit des Sizil (Prägünz) bei $100 \mathrm{~m}$ höherem Meeresstand folgendes Bild. Das Areal des ostantarktischen Festlandes war verringert: es war im ganzen ein bis wenige hundert Meter über den Meeresspiegel aufragendes Plateau, die Westantarktis war vollends zu einem Archipel ähnlich gestalteter kleinerer Inseln aufgelöst, die von der Ostantarktis durch bis $2000 \mathrm{~m}$ tiefe Meeresstraßen getrennt waren. Über diesem niedrigen Flachlandsarchipel erhoben sich einige Hochgebirge, die aber bis zur Günzeiszeit (s.o.) nicht mehr als eine beschränkte Lokalvergletscherung getragen haben dürften. Sie war eine Folge der ersten stärkeren Abkühlung der Südhalbkugel, ihre Ausbildung erfolgte daher - wie in den übrigen Vereisungsgebieten der Erde - in den frühen $\mathrm{K}$ a l t zeiten. Selbst wenn man eine starke solche erste Abkühlung annimmt, ist der Schluß auf eine sofortige starke Vergletscherung der Antarktis $\mathrm{n}$ ich t zwangsläufig (s. FaIRBridge, 1961). Denn dazu gehört eine außerdem gesicherte $\mathrm{reiche} S \mathrm{chneezufuhr}$. Zum Vergleich: die Nordpolarländer sind auch heute - wie in der Würmzeit - nur d o r t von mächtigem Inlandeis bedeckt, wo mit dem Golfstrom stets kräftige, schneeliefernde Zyklonen in die arktische Kaltlufthaube eindringen. Im heutigen Grönland liegen gerade an der dem kanadisch-polaren Kältepol zugewandten Seite weite eisfreie Flächen. Der Großteil des gerade im Bereich dieses Pols gelegenen kanadischen Archipels ist heute ebenso unvergletschert, wie es selbst zur Würmzeit der Großteil des vom Meere abgewandten mittleren und nördlichen Alaska war. Der Bereich des zweiten nordpolaren Kältepols in Ostsibirien ist heute unvergletschert und war dies auch zur Würmzeit in hohem Grade.

In der Günz-, spätestens aber in der Mindelzeit erreichte (nach dem fortschreitenden Meeresrückgang zu schließen) das antarktische Eis schon eine Höhe, mit der es Warmzeiten überdauern konnte. Damit war in den Kaltzeiten das Eindringen von Zyklonen in den $\mathrm{K}$ e $\mathrm{r} \mathrm{n}$ der verstärkten antarktischen Kaltlufthaube so erschwert, daß das Inlandeis $\mathrm{n} u \mathrm{r}$ noch in den Warmzeiten w uchs. Wir schlossen uns schon früher dieser von vielen älteren Forschern - so R. F. Scotr und Meinardus - vertretenen Theorie an. Trifft sie zu, so muß, wie Mortensen (1952) mit Recht betonte, das antarktische Inlandeis auch heute, in der Warmzeit des Holozän, eine positive Bilanz zeigen. Eben dies ist das Ergebnis. zu dem die moderne Antarktisforschung gelangte (HoinkEs, 1961, S. 369). Der mittlere Eiszuwachs ist etwas über $2 \mathrm{~cm}$ Wasseräquivalent im Jahr. Dabei ist aber die Einnahmen-Seite dieser Bilanz, die Firmakkumulation selbst in der heutigen "Warmzeit“ regional sehr verschieden: in den Randgebieten erreicht sie $50-70 \mathrm{~cm}$ im Jahr, um am Südpol selbst auf nur $7-8 \mathrm{~cm}$ im Jahr und inmitten der (von Zyklonen am seltensten berührten) zentralen Ostantarktis auf nur $3,5 \mathrm{~cm}$ Firn im Jahr zu sinken. Erwähnenswert ist endlich die Tatsache, daß in der postglazialen Wärmezeit vor 6000 Jahren das Inlandeis größer war als heute ${ }^{13}$ ). Zur Zeit eines älteren, weit bedeutenderen Hochstandes war das Inlandeis im Mittel $300 \mathrm{~m}$ mächtiger als heute, was nach Hornkes (1961) einer Massenzunahme von 15-20\% entspricht. Unter der Voraussetzung, daß der seitherige Schwund von dieser Höhe alljährlich vom gleichen negativen Bilanzwert begleitet war, wie der heutige Aufbau von dem genannten positiven, erschließt FLOHN (1963) ein eemzeitliches Alter dieses Hochstandes. Ohne diesen plausiblen Wert näher zu diskutieren, wäre er mit unserer oben dargestellten Theorie des verzögerten Wachstums durchaus vereinbar, ja er unterstriche die weiteren Folgerungen.

Die nordpolaren Inlandeisgebiete erreichten weithin im Günz und vollends in der

13) Die C14-Datierungen von getrockneten Algen aus ehemaligen Süßwassertümpeln der zugehörigen Moränen als richtig vorausgesetzt! 
Mindelzeit einen ersten, auch im Riß kaum mehr übertroffenen Hochstand mit einer entsprechenden Vergrößerung der nordpolaren Kaltluftkalotte und einer weit südwärts vorgeschobenen Polarfront mit zahlreichen Vorstößen bis in die Aquatorialregion. A Ahnliches war damals auf der Südhalbkugel noch nicht der Fall. Der thermische Äquator und der zentrale Aktionsbereich der Tropen war daher im älteren Pleistozän noch nicht so weit auf die N-Seite des Äquators verlagert, wie im jüngeren Pleistozän und in der Gegenwart. Ganz allgemein war die stark verschmälerte Tropenzone während des Pleistozän den Polarfronteinflüssen von beiden Seiten stärker unterworfen, sie war gegenüber der Tertiärzeit ein labileres, leichter verschiebbares Band.

Erst im jüngeren Pleistozän (nach den Meeresständen: von der Mindel-Riß-Warmzeit an) erreicht das antarktische Inlandeis und damit auch die antarktische Kaltluftkalotte allmählich ihren vollen Umfang. War das Inlandeis in den Warmzeiten etwas mächtiger, so war das Kaltluftreservoir sicher in den Kaltzeiten größer. Selbst heute bestehen im (gleichförmig-monatelangen) Südwinter auf der Südhalbkugel volle 25\% auch der unteren Troposhäre aus Luftmassen von um bis weit unter den Gefrierpunkt. Dieser Anteil war bei annähernd gleichem Inlandeisumfang unter Kaltzeitverhältnissen noch erheblich größer.

Aber solche Umstände fehlten früheren Kaltzeiten: sie traten erst mit dem vollendeten Aufbau des antarktischen Inlandeises im Jungpleistozän ein. Dies Eis erreichte seine größte Ausdehnung wahrscheinlich in der Eemzeit: war also zu Beginn des Würm größer als jemals seit dem Pleistozän-Beginn. Dadurch wurde (was auf der Nordhalbkugel schon im Alt- und Mittelpleistozän geschehen war) erst in der Würmzeit auch auf der Südhalbkugel die atmosphärische Zirkulation - zonal und meridional - so angeregt, daß alle Klimagürtel: die Ränder der Polarkalotte, die Zone der „braven Westwinde“, das Subtropenhoch und schließlich auch der innertropische Regengürtel stark nordwärts verschoben wurden. Anders ausgedrückt: mit dieser stärksten Abkühlung der Südhalbkugel seit Pleistozänbeginn war auch die stärkste Nordverlagerung des thermischen Aquators auf die Nordhalbkugel verbunden. Das prägte sich im Auftreten eines „äquatorialen“ Pluvials am Sahara-S-Saum aus ${ }^{14}$ ). Mit dem Beginn der Würmzeit wurden zugleich die Polarluftvorstöße aus N kräftiger. Sie erzeugten ein gleichzeitiges „polares“ Pluvial am Sahara-NSaum. Diese Vorstöße konnten jetzt zugleich den näher gerückten Åquatorialgürtel selbst auch leichter erreichen und dort durch Verstärkung tropischer Zyklone die Niederschlagsneigung steigern. Wir sehen daher im verzögerten Aufbau des antarktischen Inlandeises den Hauptgrund dafür, daß erst in der (ausgehenden Riß-, der Eem- und der) Würmzeit synchrone und zugleich dynamisch verbundene Pluviale am N- und am S-Saum der Sahara auftreten.

Mit dem Ausgang des Würm wurden von beiden Seiten die Polarlufteinflüsse geringer. Mit der Wiederverstärkung des Subtropen-Hochdruckgürtel vollzog sich eine erneute Erweiterung des saharischen Trockenraumes. Sollte es sich endlich bestätigen, daß das antarktische Inlandeis in der postglazialen Wärmezeit einen neuen Hochstand erreichte, so wäre es denkbar, daß sein indirekter Einfluß auch am Zustandekommen der jungholozänen Feuchtzeit am Sahara-S-Saum mitbeteiligt war.

14) Diese Wirkung wurde für die Eem-Zeit wahrscheinlich noch durch ein Phänomen des Nordpolargebietes gefördert. Wie FLOHN (s. u.) mitteilte, war nach arktischen Tiefsee-Bodenproben das Nordpolarmeer im letzten Interglazial von Mereis frei. Da gleichzeitig die Antarktis (durch Inlandeis) mindestens im heutigen, wahrscheinlich aber einem noch größeren Umfang eisbedeckt war, mußte sich der "thermische und dynamische Gegensatz zwischen Nord- und Südhalbkugel gegenüber heute noch verstärken. Damit verschiebt sich zugleich die innertropischen Konvergenzzone (meteorolagischer Äquator) noch mehr als heute auf die Nordhalbkugel“" (FLoHN, 1959, S. 384). 


\section{Schriftenverzeichnis}

BAKKeR, J. P.: Diskussionsbemerkungen auf dem 31. Deutschen Geographentag, Würzburg 1957. BALOuT, L.: Pluviaux interglaciaires et préhistoires saharienne. Trav. Inst. Rech. Sah., VIII, 1952. BRUNNACKER, K.: Regionale Bodendifferenzierung in Mitteleuropa während der Würmeiszeit. Eiszeitalt. u. Gegenw. 7, 1956. - - Die Würmeiszeit in Bayern im Lichte der Lößforschung. - Ber. IV. INQUA-Kongr., 1961.

BüDEL, J.: Die räumliche und zeitliche Gliederung des Eiszeitklimas. - Die Naturwissenschaften 36, 1949. - - Bericht über klima-morphologische und Eiszeitforschungen in Niederafrika. Erdk. VI, 1952. - - Reliefgenerationen und plio-pleistozäner Klimawandel im HoggarGebirge. - Erdk. IX, 1955. - - Sinai, „die Wüste der Gesetzesbildung“. - Abh. Akad. Raumforsch. u. Ld.-Plan., Bremen 28, 1956. - - Grundzüge der klimamorphologischen Entwicklung Frankens. - Wrzbg. Geogr. Arb. 4/5, 1957. - - Die Gliederung der Würmkaltzeit. - Wrzb. Geogr. Arb. 8, 1959. - - Morphogenese des Festlandes in Abhängigkeit von den Klimazonen. - Die Naturwissenschaften 48, 1961. - - Eiszeitalter und heutiges Erdbild. - Die Umschau, H. 1, 1962.

ButZer, K. W: : Quaternary stratigraphy and climate in the Near East. - Bonner Geogr. Abhandl., 24, 1958. - - Contributions to the pleistocene geology of the Nile Valley. - Erdkunde XIII, 1959.

Butzer, K. W. und Cuerda, J.: Coastal stratigraphy of Southern Mallorca and ... the p!eisto. cene chronology of the Mediterranean Sea. - J. Geol. 70, 1962.

Choubert, G.: Essai de corrélation des formations continentales et marines du pleistocène au Maroc. - Note V. Congr. INQUA, 1957.

Fatrbridge, R. W.: Convergence of evidence on climatic change and ice ages, 1961. - - New radiocarbon dates of Nile sediments. - Nature, 196, No. 4850, 1962.

Fink, J.: Die Gliederung des Jungpleistozän in Österreich. - Mitt. geol. Ges. Wien, 54, 1962.

Flint, R. F.: Glacial and pleistocene Geology. - J. Wiley \& Sons, New ftork 1957. - - Pleistocene climates in low latitudes. Geogr. Review, Jan. 1963.

FloHN, H.: Atmosphärische Zirkulation und Paläoklimatologie. - Geol. Rundsch. 40, 1952. - Zur meteorologischen Interpretation der pleistozänen Klimaschwankungen. - Eiszeitalter u. Gegenw., 14, 1963. - - Kontinental-Verschiebungen, Polwanderungen und Vorzeitklimate im Lichte paläomagnetischer Meßergebnisse. - Naturwiss. Rundsch. 12, 1959.

GelleRt, J. F.: Kurze Bemerkungen zur Klimazonierung der Erde und zur planetarischen Zirkulation der Atmosphäre in der jüngeren erdgeschichtlichen Vorzeit, ausgehend vom Tertiär. - Wiss. Ztschr. Päd. Hochsch. Potsdam, 3, 1958.

Glaser, U.: Die untermiozäne Strandzone am Südsaum der Schwäbischen Alb. - Diss. Univ. Würzburg, 1963.

Graul, H.: Der Verlauf des glazialeustatischen Meeresspiegelanstiegs, berechnet an Hand von Cl4-Datierungen. - Wiss. Abh. Dt. Geographentag 33, 1959. - - Eine Revision der pleistozänen Stratigraphie des schwäbischen Alpenvorlandes. - Pet. Mitt. 106, 1962.

HACK, J. T.: Geologic evidence of late pleistozene climates. - Climatic changes, ed. by Harlow Shapley, Harvard University Press, Cambridge, 1953.

HövermanN, J.: Über glaziale und "periglaziale" Erscheinungen in Erithrea und Nordabessinien. Abh. Akad. Raumforsch. u. Ld.-Plan., Bremen, 28, 1954.

KNeTsCh, G.: Beobachtungen in der Lybischen Wüste. Geol. Rundschau 38, 1950. - - Geohydrological Groundwater Investigations in North-African desert regions by means of complex methods. UN-Conference in Apll. of Sc. and Technology for the benefit of the less developed Areas, 1962.

Körber, H.: Die Entwicklung des Maintals. Wrbg. Geogr. Arb. 10, 1963.

KubienA, W. L.: Über die Braunlehmrelikte des Atakor (Hoggar-Gebirge, Zentral-Sahara). Erdkunde IX, 1955. - - Polygenetische Bodenkunde und Aufbauelemente der Tropenböden. - Vortrag Univ. Hamburg am 12. 12. 1962. - - Die Genese lateritischer Profile als bodenkundliches Problem. Vortrag vor der Ges. Dt. Metallhütten-Bergleute, Würzburg, 1963.

Lefranc, J. P.: De Zuila aux lacs de la Marzoukia. - Trav. Inst. Rech. Sah. XV, 1, 1957.

Mauny, M. R.: Sur la préhistoire de la presq⿳1̂le du Cap-Vert. - Etudes Sénégalais. 1. IFAN, Dakar, 1949.

Mensching, H.: Morphologische Studien im Hohen Atlas von Marokko. - Wrzbg. Geogr. Arb. 1, 1953. - - Das Quartär in den Gebirgen Marokkos. - Pet. Mitt. Erg.-H. 256, 1955. - Geomorphologie der Hohen Rhön und ihres südlichen Vorlandes. Wrzb. Geogr. Arb. 3/4, 1957. - - Glacis-Fußfläche-Pediment. - Z. Geomorph. 2, 1958. - - Bericht und Ge-danken zur Tagung der Kommission für Periglazialforschung in der IGU in Marokko. 19.-31. 10. 1959. - Z. Geomorph. 4, 1960.

Mortensen, H.: Heutiger Firnrückgang und Eiszeitklima. - Erdkunde VI, 1952. 
QuÉzel, P. ET Martinez, Cl.: Pollenanalytische Untersuchungen in der Sahara. Zitiert nach VAN ZINDEREN-BAKKEI, 1962, S. 23 u. 68.

Kutre, E.: Die Geologie des Schienerberges (Bodensee) und der Öhninger Fundstätten. N. Jb. Geol. Pal., Abh., 102, 1956. - - Mikrofossilien in Süßwassersedimenten. - Geol. Rundsch. 51 (dort auch weitere Literatur), 1961. - - Freundl. mündliche Zusatzmitteilungen am 20. 3. 1963.

PFannenstiel, M.: Das Quartär der Levante, Teil II. Akad. d. Wiss. u. Lit. Mainz. - Abh. Math.Nat. Kl. Nr. 7, 1963.

Schindewolf, O. H.: Darwins Abstammungslehre in der Sicht eines Paläontologen. - Universitas $15,1960$.

Schwarzbach, M.: Das Klima der Vorzeit. - 2. Aufl. F. Enke Verlag, Stuttgart 1961. - - Das Alter der Wüste Sahara. - Neues Jb. Geol. Paläont., Mh., 1953.

Sickenberg, O.: Freundl. mündliche Mitteilung, 1951.

WILhelmy, H.: Klimamorphologie der Massengesteine. - G. Westermann Verlag, Braunschweig 1958.

WinkLeR-Hermaden, A.: Geologisches Kräftespiel und Landformung. - Springer Verlag, Wien 1957.

WirthmanN, A.: Die Landformen der Edge-Insel in SO-Spitzbergen. Habil.-Schrift, Würzburg 1962.

WRIGHT, H. E. jr.: Late pleistocene soil development, glacial and cultural change in the eastern Mediterranian Region. - Ann. New York Academy Sci., 1961.

Woldstedt, P.: Das Eiszeitalter. Grundlinien einer Geologie des Quartärs. 3. Aufl. Bd. I, Enke Verlag Stuttgart, 1961.

Wüst, G.: Der Ursprung der atlantischen Tiefenwässer. - Z. Ges. Erdk. Berlin, Sonderbd. z. 100Jahr-Feier, 1928.

van Zinderen-BAKKer, E. M.: Palynology in Africa, seventh report (1960 and 1961). - Bloemfontein, October 1962. - - Pflanzengeographische Probleme des afrikanischen Quartärs (insbesondere der Berggebiete). Bot.-geograph.-geolog. Kolloquium, Würzburg, 20. 6. 1963.

Manuskr. eingeg. 28. 3. 1963.

Anschrift des Verf.: Prof. Dr. J. Büdel, 87 Würzburg, Klinikstraße 3, Geogr. Institut. 